\title{
Reduced miR-26b Expression in Megakaryocytes and Platelets Contributes to Elevated Level of Platelet Activation Status in Sepsis
}

\author{
Bernadett Szilágyi ${ }^{1,2, \dagger}$, Zsolt Fejes ${ }^{1,2,+} \oplus$, Szilárd Póliska ${ }^{3}\left(\mathbb{D}\right.$, Marianna Pócsi ${ }^{1}$, \\ Zsolt Czimmerer ${ }^{3}$, Andreas Patsalos ${ }^{4}{ }^{\oplus}$, Ferenc Fenyvesi ${ }^{5,6}$, Ágnes Rusznyák ${ }^{5,6}$, György Nagy ${ }^{7}$, \\ György Kerekes ${ }^{8}$, Mariann Berhés ${ }^{7}$, Ildikó Szúcs ${ }^{9}$, Satya P. Kunapuli ${ }^{10}$, János Kappelmayer ${ }^{1,2}$ \\ and Béla Nagy Jr. ${ }^{1,2, *}$ \\ 1 Department of Laboratory Medicine, Faculty of Medicine, University of Debrecen, \\ H-4032 Debrecen, Hungary; sz.bernadett27@gmail.com (B.S.); fejes.zsolt@med.unideb.hu (Z.F.); \\ pmarcsi89@gmail.com (M.P.); kappelmayer@med.unideb.hu (J.K.) \\ 2 Kálmán Laki Doctoral School of Biomedical and Clinical Sciences, Faculty of Medicine, University of \\ Debrecen, H-4032 Debrecen, Hungary \\ 3 Department of Biochemistry and Molecular Biology, Genomic Medicine and Bioinformatics Core Facility, \\ Faculty of Medicine, University of Debrecen, H-4032 Debrecen, Hungary; poliska@med.unideb.hu (S.P.); \\ czimmerer@gmail.com (Z.C.) \\ 4 Department of Medicine, Johns Hopkins University School of Medicine, Institute for Fundamental \\ Biomedical Research, Johns Hopkins All Children's Hospital, St. Petersburg, FL 33701, USA; \\ apatsalos@jhmi.edu \\ 5 Department of Pharmaceutical Technology, Faculty of Pharmacy, University of Debrecen, \\ H-4032 Debrecen, Hungary; fenyvesi.ferenc@pharm.unideb.hu (F.F.); \\ rusznyak.agnes@pharm.unideb.hu (Á.R.) \\ 6 Doctoral School of Pharmaceutical Sciences, University of Debrecen, H-4032 Debrecen, Hungary \\ 7 Department of Anesthesiology and Intensive Care, Faculty of Medicine, University of Debrecen, \\ H-4032 Debrecen, Hungary; gynagy1986@gmail.com (G.N.); bermarjan@yahoo.co.uk (M.B.) \\ 8 Institute of Internal Medicine, Faculty of Medicine, University of Debrecen, H-4032 Debrecen, Hungary; \\ gkerekesg@gmail.com \\ 9 Department of Pulmonology, Faculty of Medicine, University of Debrecen, H-4032 Debrecen, Hungary; \\ ildiks@yahoo.com \\ 10 Department of Physiology and Sol Sherry Thrombosis Center, Temple University School of Medicine, \\ Philadelphia, PA 19140, USA; spk@temple.edu \\ * Correspondence: nagy.bela@med.unideb.hu; Tel.: +36-52-340-006 \\ $\dagger$ These authors contributed equally to this work.
}

Received: 31 December 2019; Accepted: 26 January 2020; Published: 29 January 2020

Abstract: In sepsis, platelets may become activated via toll-like receptors (TLRs), causing microvascular thrombosis. Megakaryocytes (MKs) also express these receptors; thus, severe infection may modulate thrombopoiesis. To explore the relevance of altered miRNAs in platelet activation upon sepsis, we first investigated sepsis-induced miRNA expression in platelets of septic patients. The effect of abnormal Dicer level on miRNA expression was also evaluated. miRNAs were profiled in septic vs. normal platelets using TaqMan Open Array. We validated platelet miR-26b with its target SELP (P-selectin) mRNA levels and correlated them with clinical outcomes. The impact of sepsis on MK transcriptome was analyzed in MEG-01 cells after lipopolysaccharide (LPS) treatment by RNA-seq. Sepsis-reduced miR-26b was further studied using Dicer1 siRNA and calpain inhibition in MEG-01 cells. Out of 390 platelet miRNAs detected, there were 121 significantly decreased, and 61 upregulated in sepsis vs. controls. Septic platelets showed attenuated miR-26b, which were associated with disease severity and mortality. SELP mRNA level was elevated in sepsis, especially in platelets with increased mean platelet volume, causing higher P-selectin expression. Downregulation of Dicer1 generated lower miR-26b with higher SELP mRNA, while calpeptin restored miR-26b in MEG-01 
cells. In conclusion, decreased miR-26b in MKs and platelets contributes to an increased level of platelet activation status in sepsis.

Keywords: platelet activation; microRNA; SELP; megakaryocyte; sepsis; inflammation; MEG-01

\section{Introduction}

Sepsis is a life-threating condition with dysregulated systemic host response to microbial pathogens, while the septic shock is a subset of sepsis with circulatory, metabolic, and cellular abnormalities [1]. As a consequence, multi-organ failure may rapidly develop, resulting in early death. Altered platelet count and function are critical in this disease that contributes to sepsis-associated mortality [2]. However, platelet function in sepsis has yielded conflicting data based on previous studies. Human septic platelets have shown increased surface P-selectin expression causing high soluble P-selectin plasma levels [3], elevated thrombospondin exposure [4], and augmented platelet reactivity at early time points of the disease [5]. In contrast, hyporeactive platelets with decreased ex vivo aggregability have been reported in sepsis by others [6,7]. Whereas, an elevated level of platelet activation status in sepsis is not questioned that is associated with the upregulation of several platelet receptors [8]. P-selectin is involved in the formation of heterotypic aggregates [9], and their increased expression is associated with a higher risk for mortality, especially in older septic patients [10]. Elevated soluble P-selectin levels show a strong correlation with infection and disease severity in sepsis with coagulation disorders [11].

Based on the etiology of insults of sepsis, the pathogen-associated molecular patterns and damage-associated molecular patterns can be distinguished [1]. Among both conditions, similar mediators are released that react primarily with toll-like receptors (TLRs). Most TLR members, e.g., TLR4, are expressed on both platelets and megakaryocytes (MKs) [12]. Therefore, platelets participate in the amplified inflammatory and immune response during sepsis [13], while infection can also modulate thrombopoiesis via the TLR2 receptor [14]. Platelet hyperactivity may turn into thrombocytopenia because of neutrophil-dependent sequestration of activated platelets into the lungs in a TLR4-dependent manner [12].

Platelets carry a large number of microRNAs (miRNAs), messenger RNAs (mRNAs), and several proteins involved in miRNA processing (e.g., Dicer), which are delivered from MKs $[15,16]$. Expression of altered miRNAs correlates with platelet reactivity [17], while Dicer1-mediated miRNAs are able to regulate target mRNAs and de novo synthesis of proteins being important for the hemostatic function of platelets [18]. Accordingly, the expression of RNAs and related proteins are not static in platelets and can be modulated upon platelet activation [19]. Among in vitro septic conditions, mRNA levels of IL1B (interleukin-1 $\beta$, IL-1 $\beta$ ) and F3 (tissue factor) are increased, and resulting proteins are translated and accumulated in human platelets in response to TLR4 agonist lipopolysaccharide (LPS) $[20,21]$. Based on recent in vivo experiments, transcriptional and translational properties of human and murine platelets are significantly affected by sepsis, causing de novo synthesis of $\alpha \mathrm{IIb}$ protein with integrin $\alpha \mathrm{IIb} \beta 3$ activation [22]. However, there is no available data about how the platelet miRNA profile is altered in sepsis that, in turn, modulates target mRNA levels and platelet function.

In this study, the miRNA profile was characterized for the first time in platelets of septic patients in comparison to healthy controls. We then validated the expression of miR-26b in septic platelets with target SELP mRNA level that encodes P-selectin, a receptor for P-selectin glycoprotein ligand-1 [9]. This platelet miRNA was further analyzed in relation to disease severity and sepsis-related mortality. The functional relationship between miR-26b and SELP expression was proved among septic conditions using specific miRNA mimics. In parallel, the transcriptome of MKs in sepsis was also investigated by RNA-seq using MEG-01 cell cultures in response to LPS. Changes in the Dicer1 level were analyzed in septic platelets and LPS-induced MEG-01 cells for its contribution to altered miRNA levels. For this 
purpose, two experimental approaches were also applied in MEG-01 cells among septic conditions: i) downregulation of DICER1 expression by siRNA and ii) administration of specific calpain inhibitor (calpeptin) during LPS treatment. Finally, a gene ontology (GO) analysis was performed to study the role of upregulated SELP expression in MK function in sepsis.

\section{Results}

\subsection{Baseline Characteristics of Study Groups}

Inflammation-dependent laboratory parameters (i.e., white blood cell (WBC) count, serum C-reactive protein (CRP), and procalcitonin (PCT)) were significantly elevated in septic subjects vs. controls (Table 1). Eighteen out of 21 subjects suffered from sepsis with pneumonia. As expected, the mean platelet count was significantly lower in the sepsis group $(p<0.01)$ than controls; however, many individual values were still within the reference range at the time of recruitment. Importantly, there was no difference in terms of administration of anti-platelet medication (e.g., aspirin, clopidogrel) between the two groups; thus, we could exclude the modulation of these regimens on platelet activation and related miRNA levels [23]. In a patient cohort, 14 individuals suffered from sepsis, while septic shock developed in seven cases, and nine subjects died of these severe clinical conditions within 28 days despite ICU treatment. In contrast, control subjects had no inflammation at the time of enrollment (Table 1).

Table 1. Summary of demographical and clinical characteristics of septic and control study groups. Data are expressed as median with (IQR, interquartile range), or mean $\pm \mathrm{SD}$ as appropriate. Sequential organ failure assessment (SOFA) score was applied to determine the extent of organ function or rate of failure. For statistical analysis, we used Student's t-test or Mann-Whitney U test and Chi-square test as appropriate. WBC: white blood cell; PLT: platelet; CRP: C-reactive protein; PCT: procalcitonin; ICU: intensive care unit; n.s., not significant; n/a, not applicable.

\begin{tabular}{|c|c|c|c|}
\hline Parameters & Septic Patients $(n=21)$ & Controls $(n=21)$ & $p$ Value \\
\hline Age (years) & $64(51-70)$ & $58(42-65)$ & n.s. \\
\hline Male/female gender $(n)$ & $16 / 5$ & $14 / 7$ & n.s. \\
\hline WBC count $(\mathrm{G} / \mathrm{L})$ & $11.4(8.3-16.2)$ & $7.6(6.2-8.9)$ & $p<0.001$ \\
\hline PLT count (G/L) & $218(175-264)$ & $332(290-365)$ & $p<0.01$ \\
\hline Serum CRP (mg/L) & $210.5 \pm 98.2$ & $1.4 \pm 1.0$ & $p<0.001$ \\
\hline Serum PCT $(\mu \mathrm{g} / \mathrm{L})$ & $27.4 \pm 11.7$ & $\mathrm{n} / \mathrm{a}$ & - \\
\hline SOFA-score & $11(9-13)$ & $\mathrm{n} / \mathrm{a}$ & - \\
\hline Sepsis/septic shock $(n)$ & $14 / 7$ & $\mathrm{n} / \mathrm{a}$ & - \\
\hline ICU length of stay (days) & $25.1 \pm 14.4$ & $\mathrm{n} / \mathrm{a}$ & - \\
\hline 28-day mortality $(n)$ & 9 & $\mathrm{n} / \mathrm{a}$ & - \\
\hline Source of infection-pneumonia $(n)$ & 18 & $\mathrm{n} / \mathrm{a}$ & - \\
\hline Source of infection-urinary tract $(n)$ & 3 & $\mathrm{n} / \mathrm{a}$ & - \\
\hline Organism-Gram-positive bacteria $(n)$ & 6 & $\mathrm{n} / \mathrm{a}$ & - \\
\hline Organism-Gram-negative bacteria $(n)$ & 12 & $\mathrm{n} / \mathrm{a}$ & - \\
\hline Unknown infection $(n)$ & 3 & $\mathrm{n} / \mathrm{a}$ & - \\
\hline Anti-platelet therapy $(n)$ & 16 & 12 & n.s. \\
\hline
\end{tabular}

Increased level of platelet activation was detected in septic patients based on elevated surface P-selectin expression $(p<0.0001)$, and higher plasma concentrations of soluble P-selectin $(p<0.0001$, $n=10$ /group) in contrast to healthy controls (Figure 1A,B). In addition, increased mean platelet volume (MPV) values $(p<0.0001)$ were measured in the septic cohort vs. normal controls, reflecting an 
increased pool of larger and younger circulating platelets (Figure 1C), which could be more reactive than smaller counterparts [24].
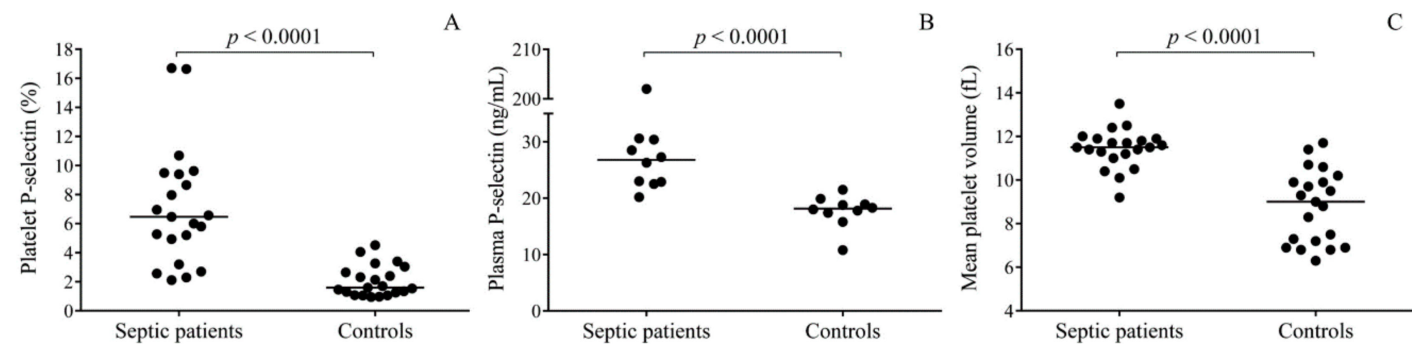

Figure 1. Evaluation of the level of platelet activation status in septic patients $(n=21)$ via surface P-selectin positivity (A) and soluble P-selectin levels (B) measured in some selected plasma samples ( $n=10$ /group) in comparison to controls. Mean platelet volume values were also analyzed to estimate the pool of larger and younger platelets $(C)$. All these parameters were significantly higher than controls, suggesting an enhanced level of platelet activation status after the development of sepsis. Dots represent single results, and median values are depicted. Mann-Whitney U test was performed for comparison.

\subsection{Sepsis-Induced Changes in Platelet miRNAs}

Our aim was to investigate the regulation of abnormal platelet phenotype with enhanced P-selectin expression in sepsis via measuring the level of platelet miRNAs that might be involved in platelet function. Therefore, we here profiled miRNA expression for the first time in platelets from septic patients and examined the relevance of their altered levels to elevated platelet activation status. First, a comprehensive analysis of miRNAs was performed by TaqMan Open Array in three randomly selected RNA samples of each study group to screen which platelet miRNAs were significantly altered in sepsis compared to control subjects. We considered miRNA expression significantly altered when at least 1.5-fold change was observed. Out of 754 miRNAs, 390 miRNAs could be detected in these samples: there were 121 whose levels were significantly decreased, and 61 upregulated miRNAs in septic platelets (Figure 2A). Accordingly, platelet miR-26b was found to be downregulated, which is among the 10 most abundant miRNAs in platelets [25]. In addition, miR-26b regulates P-selectin expression via regulating the SELP mRNA level [26]. In Supplementary Table S1, significantly altered and unchanged miRNAs of septic platelets are listed. Expression of platelet miR-26b was then validated in each enrolled septic patient, and significantly attenuated levels $(p=0.002)$ were analyzed compared to controls (Figure 2B).

To confirm the effect of septic milieu on platelet miRNA level, purified normal platelets were activated with TLR4 agonist LPS in combination with lipoprotein binding protein (LBP) and soluble $\mathrm{CD} 14$ at $37^{\circ} \mathrm{C}$ or PBS (vehicle) for $4 \mathrm{~h}$ in vitro. For positive control, tumor necrosis factor (TNF)- $\alpha$ was applied to trigger platelet activation. Platelet miR-26b was significantly reduced in response to either agonist (Supplementary Figure S1A). These results were in agreement with data of ex vivo septic platelets, suggesting that LPS acted as a direct platelet activator and could alter RNA expression in sepsis, similar to former findings [20]. 
A
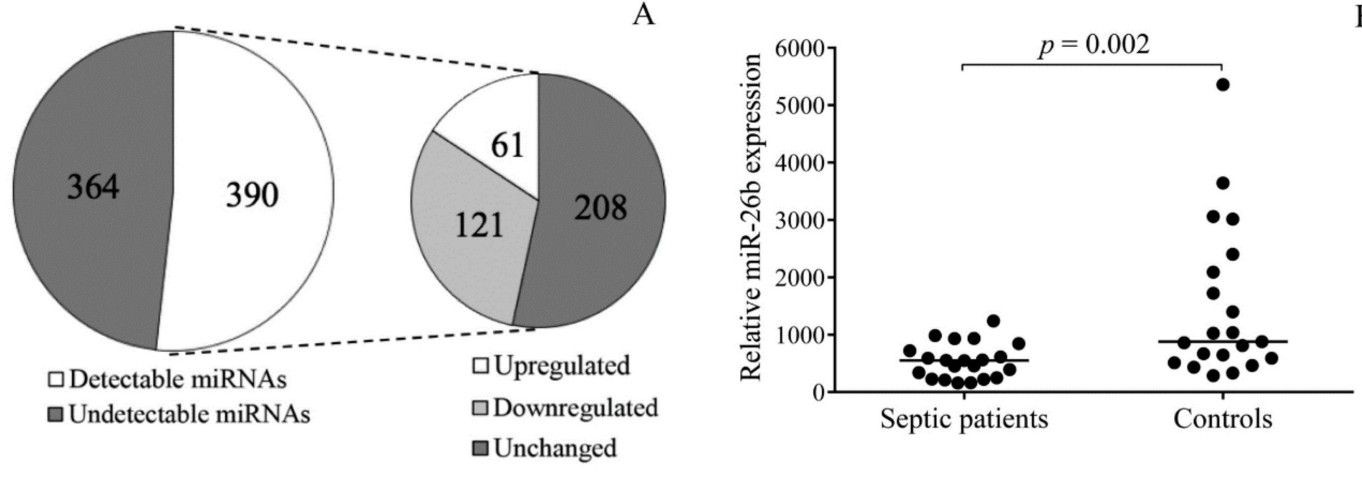

B

C
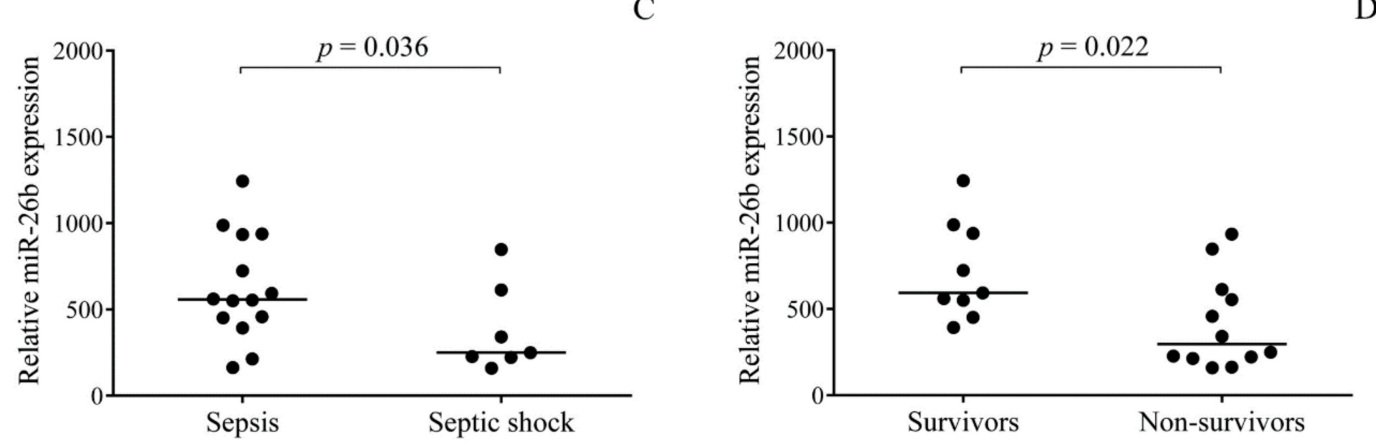

Figure 2. Analysis of abnormal platelet miRNA expression induced by sepsis. First, miRNAs were profiled by TaqMan Open Array in three septic and control samples (A). Out of 390 detected, there were 121 significantly downregulated and 61 upregulated miRNAs in septic platelets. Platelet miR-26b (B) was validated in both study groups ( $n=21$ /group), showing attenuated levels in sepsis. Alterations in miRNA expression were further observed in the septic cohort in relation to disease severity (C) and sepsis-related mortality (D). Levels of miR-26b reflected septic shock and early death. Dots represent single expression values. Median values are depicted. Mann-Whitney $U$ test was performed for comparison.

\subsection{Platelet miR-26b Expression Correlates with Sepsis Severity and Mortality}

We next investigated whether changes in platelet miR-26b expression were associated with the severity of sepsis and the clinical outcome in the presence of elevated platelet P-selectin positivity. Patients were separately analyzed based on the progression of their disease, i.e., sepsis $(n=14)$ or septic shock $(n=7)$. Significantly lower levels of miR-26b were found in patients who had septic shock than sepsis $(p=0.036)$ (Figure 2C). When we sub-grouped septic individuals into 'survivors' $(n=9)$ and 'non-survivors' $(n=12)$ cohorts according to 28-day mortality, even lower platelet miR-26b expression $(p=0.022)$ was measured in early death compared to surviving patients (Figure 2D). These results suggested that there was a remarkable alteration in the expression of platelet miR-26b in connection with the severity and mortality of sepsis.

\subsection{SELP Expression is Upregulated in Platelets with Sepsis}

We then asked whether changes in the expression of target mRNA of miR-26b could be also observed in these septic platelets; thus, the expression of SELP was quantified by RT-qPCR. As the level of IL1B mRNA was earlier revealed to be processed and accumulated in sepsis-induced platelets [20], that is why IL1B expression was parallelly studied that was substantially induced $(p=0.002)$ in the ex vivo sepsis samples (Figure 3A). Importantly, SELP mRNA targeted by miR-26b [26] was upregulated in sepsis $(p<0.001)$ relative to healthy platelets (Figure 3B). Furthermore, higher SELP and IL1B mRNA levels were observed in the case of in vitro stimulated normal platelets by LPS (Supplementary Figure S1B,C). Accordingly, TLR4 signaling dependent platelet activation events were 
associated with induced SELP expression. Platelet SELP mRNA levels were higher in subjects who suffered from septic shock (Figure 3C) or did not survive (Figure 3D), but these differences did not reach a statistical significance probably due to the limited number of patients. When we compared SELP expression based on the values of MPV, significantly higher SELP mRNA levels $(p=0.008)$ were found in those showing larger than normal MPV values ( $\geq 11.1 \mathrm{fL}$ ) (Figure $3 \mathrm{E}$ ).
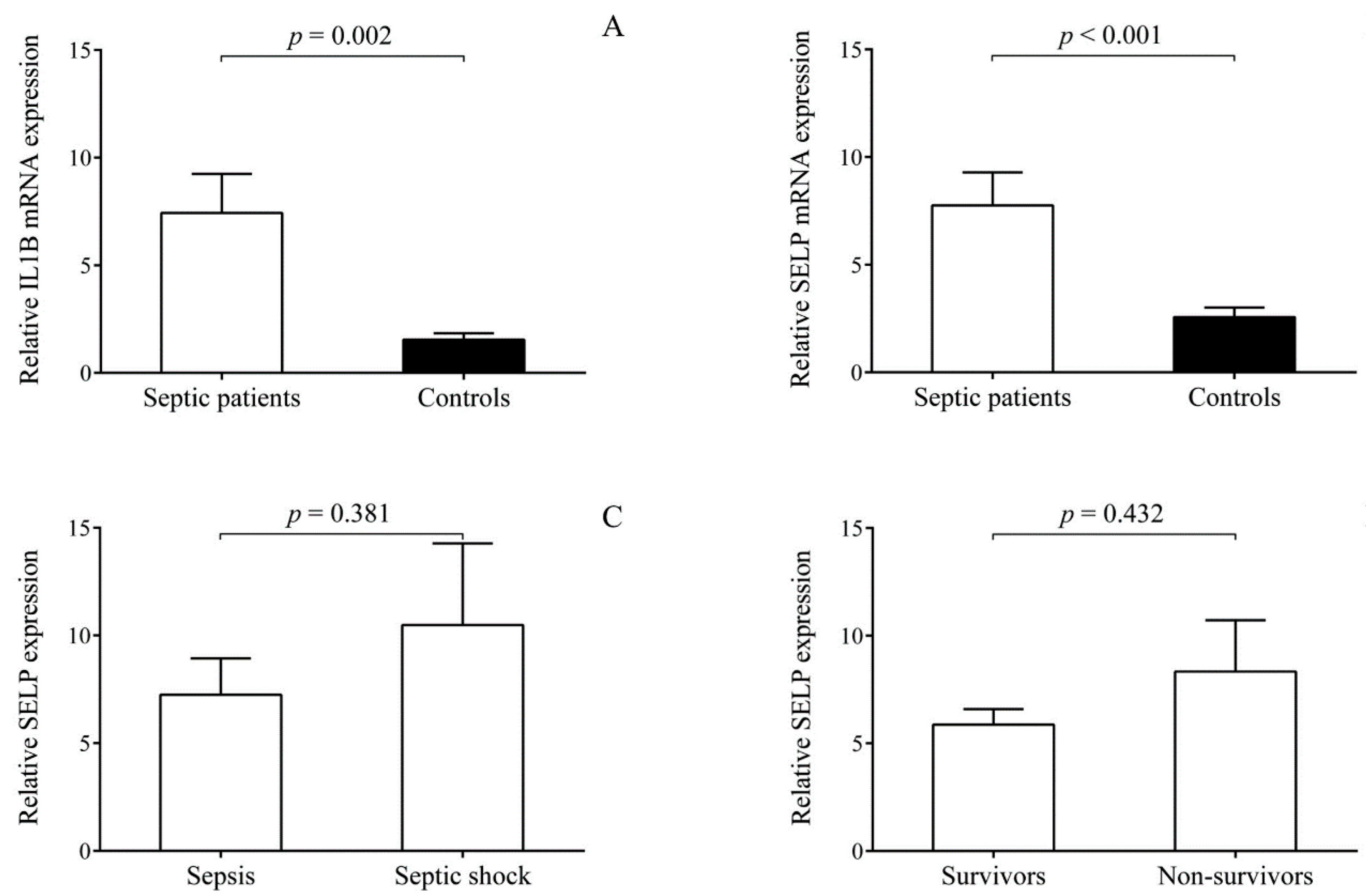

$\mathrm{C}$
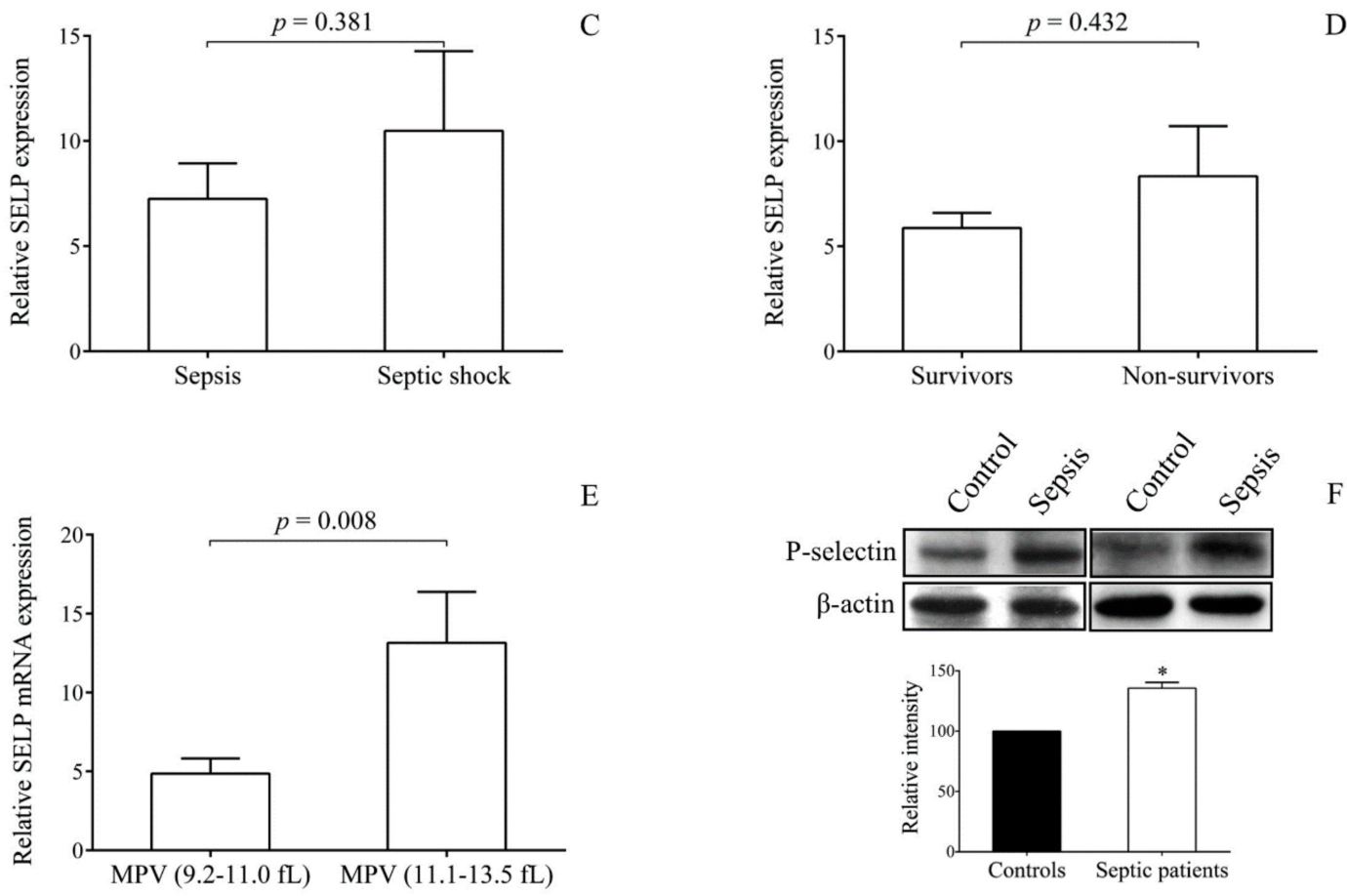

Figure 3. Increased $S E L P$ and P-selectin protein expression in septic platelets. Platelets of septic patients $(n=21)$ showed elevated levels of IL1B (A) and SELP mRNA (B) levels compared to control platelets. There was a tendency for higher platelet SELP expression in those sepsis individuals who had septic shock (C) or died by sepsis (D). In addition, significantly elevated SELP mRNA levels were observed in platelets with larger than normal MPV values $(n=8)(E)$. Western blot analysis of platelet lysates obtained after $72 \mathrm{~h}$ of sepsis onset $(n=5)$ demonstrated increased expression of P-selectin protein compared to normal samples $(\mathbf{F})$. Mean \pm SEM was depicted, ${ }^{*} p<0.05$. Mann-Whitney $U$ test or unpaired $t$-test was performed for the comparisons.

Due to the increased SELP expression in patient platelets after the development of sepsis, we wondered whether P-selectin at protein level could be also detected at a higher quantity in platelets. We found that platelet lysates obtained after $72 \mathrm{~h}$ of the onset of sepsis showed a significantly larger amount of P-selectin compared to control specimens using Western blotting (Figure 3F). These results suggested that more P-selectin was available in larger (i.e., newly synthesized) platelets that could provide excessive functional responses with higher P-selectin expression in sepsis $[3,8]$. 


\subsection{TLR4 Modulated Transcriptome in MEG-01 Cells Via Nuclear Factor-Kappa B (NF-kB) Pathway}

In order to confirm the cellular activation of MEG-01 cells by LPS via the nuclear factor-kappa B (NF-kB) pathway, first, the nuclear translocation of p65 was visualized by fluorescence microscopy. As a positive control, TNF- $\alpha$ treatment was used in the same settings. There was an enhanced nucleus/cytosol intensity for p65 after LPS or TNF- $\alpha$ vs. baseline (PBS) samples (Figure 4A,B).

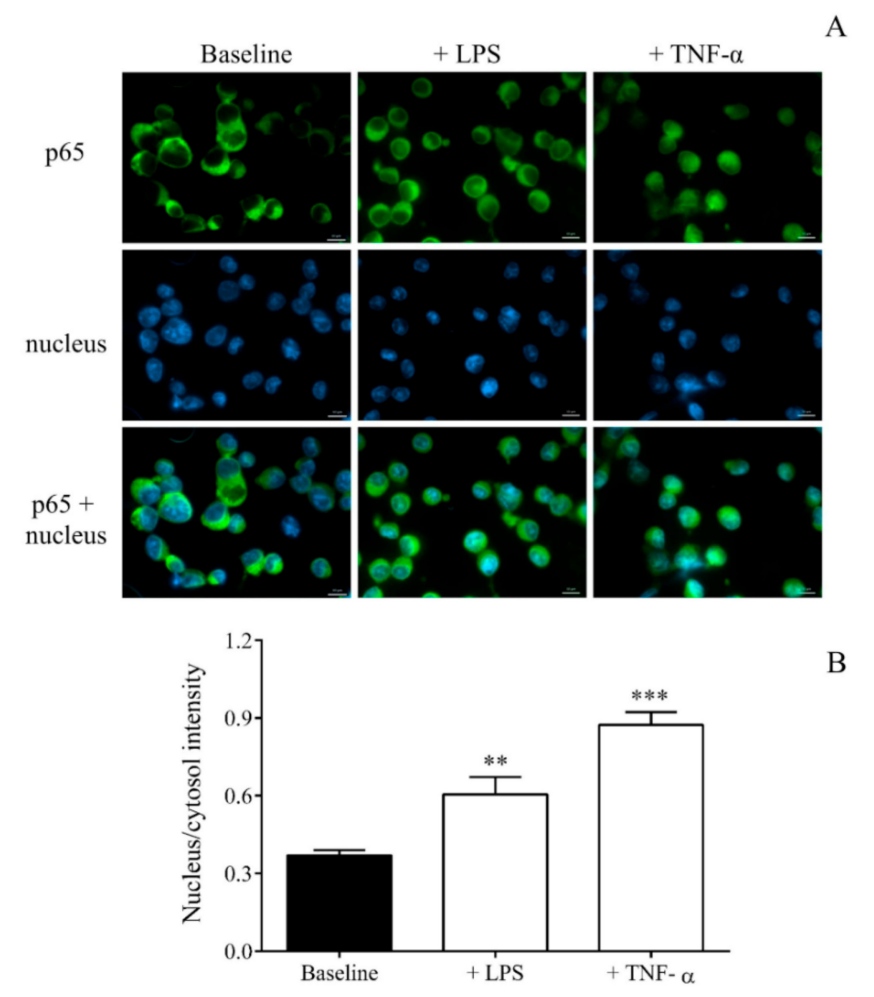

Figure 4. Immunohistochemical staining and analysis of the nuclear factor kappa B (NF- $\kappa \mathrm{B})$ pathway activation in LPS or TNF- $\alpha$ treated MEG-01 cells. Megakaryocytes were stimulated with PBS (baseline), $100 \mathrm{ng} / \mathrm{mL}$ LPS or TNF- $\alpha$ for $4 \mathrm{~h}$. Nuclear localization of the NF- $\mathrm{kB}$ p65 subunit was monitored by immunostaining. Green: p65 staining; blue: cell nuclei. Scale bar: $20 \mu \mathrm{m}$ (A). The ratio of the fluorescence intensity of the NF- $\mathrm{KB}$ immunostaining in cell nuclei and cytosol was analyzed (B). Mean \pm SEM, $n=6-10$ /group. ${ }^{* *} p<0.01$ and ${ }^{* * *} p<0.001$ based on statistical analyses.

To explore the functional impact of altered RNA expression at the level of MK in sepsis, we thoroughly investigated LPS-induced transcriptional changes in MEG-01 cells. We stimulated MEG-01 cell cultures with LPS for $4 \mathrm{~h}$ and determined their transcriptome by RNA-seq. Transcriptomic and differential expression analysis by RNA-seq revealed 1414 differentially expressed (DE) genes (Figure 5A). More specifically, we identified 354 significantly upregulated and 1060 significantly downregulated transcripts in LPS-activated MEG-01 cells at a fold change of $\geq 1.5$ compared to untreated cells (Figure 5A, Supplementary Table S2). A clustered heatmap with the top 50 differentially expressed genes is shown in Figure 5B. These results revealed that there might be substantial alterations in the MK transcriptome during sepsis. 
A
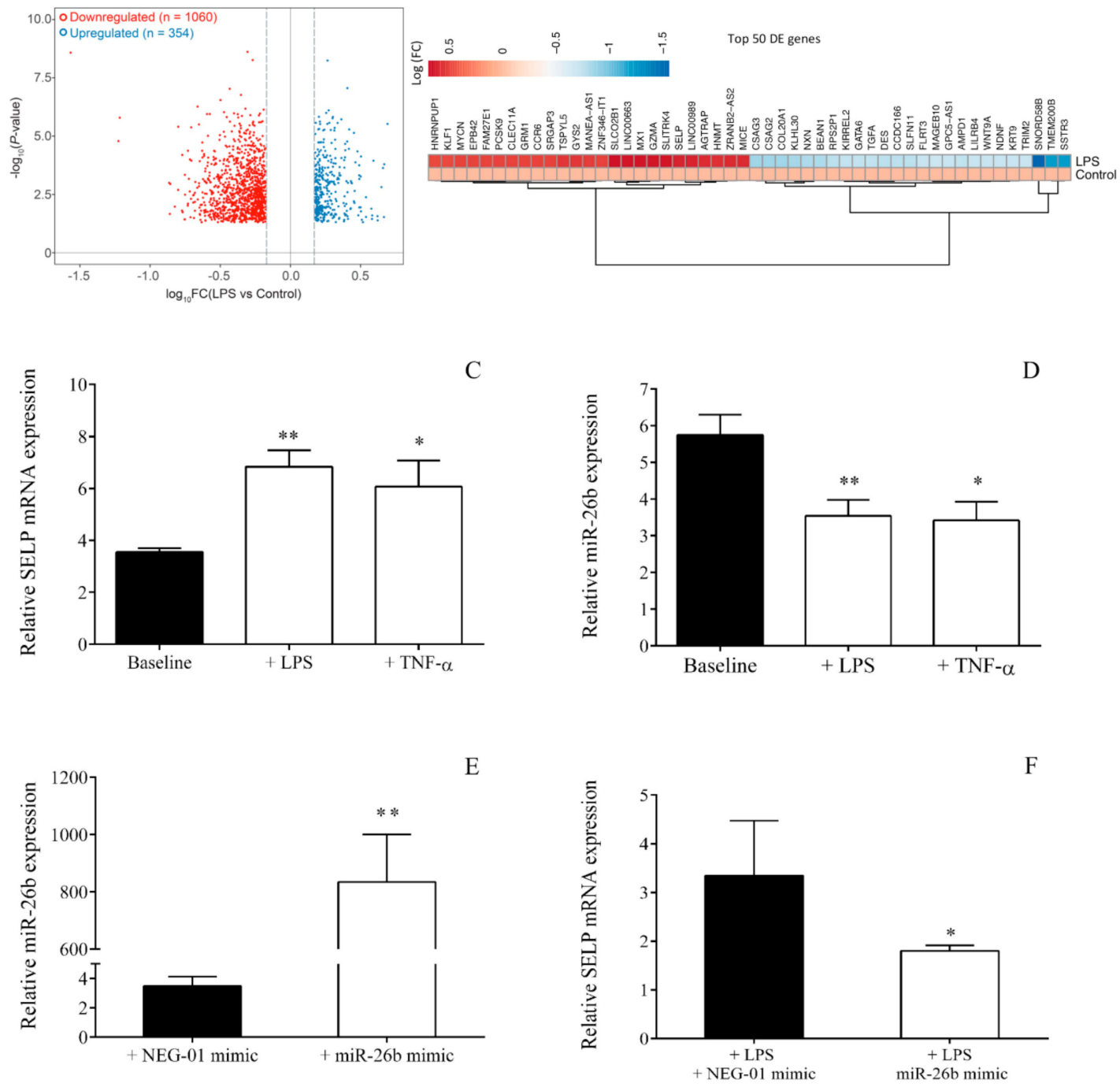

Figure 5. Toll-like receptor (TLR) 4 pathway induced changes in mRNA and miRNA expression of MEG-01 cells. Volcano plot depicting the number of differently expressed genes in untreated and lipopolysaccharide (LPS)-treated MEG-01 cells ( $n=3$ /condition) at $4 \mathrm{~h}$, observed by RNA-seq analysis, quantified by the DESeq method and plotted based on Log10 (Fold Change) and -log ( $p$-value). There were 354 significantly upregulated, and 1060 downregulated transcripts in LPS-activated MEG-01 cells compared to control cells at a fold change (FC) of $\geq 1.5$. Dotted lines indicate FC cut-off (A). Clustered heat map of the top 50 differentially expressed genes in LPS-treated MEG-01 cells at $4 \mathrm{~h}$. Genes were displayed as Log (Fold Change) (B). We then validated SELP expression in MEG-01 cells after LPS treatment ( $n=6-8$ /experiment), and TNF- $\alpha$ stimulation was used as a positive control (C). In parallel, miR-26b was significantly attenuated by LPS or TNF- $\alpha$ vs. untreated cells (D). These results were in accordance with the findings in ex vivo septic platelets. The functional relationship between miR-26b and SELP expression was analyzed using specific miRNA mimic transfection in LPS-stimulated MEG-01 cell cultures. The overexpression of miR-26b by mimic (E) resulted in lowered SELP mRNA levels compared to samples with control NEG-01 mimic (F). Mean \pm SEM was depicted, * $p<0.05,{ }^{* *} p<0.01$ based on statistical analyses.

To assess the biological response and functions that TLR4-activated MKs could gain at the level of gene expression, we extended our study with pathway analysis of the altered genes in MEG-01 cells after 4-h LPS stimulation, using the gene ontology resource database (Supplementary Figure S2). Interestingly, LPS treatment significantly affected genes associated with the activation of several 
inflammatory pathways involving cell responses to TNF- $\alpha$, IL-1 $\beta$, interferon-gamma, and LPS, as well as gene changes associated with leukocyte migration and chemotaxis (Supplementary Figure S2), all indicative of a potential acquisition of a pro-inflammatory-like phenotype. Other notable pathways affected in MKs in response to TLR4 agonist included genes changes associated with response to calcium, lipid homeostasis, angiogenesis, and the MAPK, ERK1/2, and JNK signaling pathways. Importantly, SELP, which was significantly upregulated in MKs in response to LPS, could be implicated in several different predicted pathways, highlighted in Supplementary Figure S2, including the ones in response to LPS and inflammation, leukocyte adhesion and migration, as well as implications with sequestering calcium ions. Hence, the TLR4-dependent pathway could substantially modulate gene expression in MKs [27] and might act as a potential link between the inflammatory environment and altered gene expression profile of this cell type. These findings also supported that $S E L P$, encoding a key cellular adhesion molecule P-selectin, had a central role in the regulation of inflammatory signaling of MKs upon sepsis. To verify the reproducibility of our RNA-seq analysis, we validated the expression of SELP in LPS-stimulated MKs that showed a significant rise (Figure 5C).

\subsection{Sepsis-Reduced miR-26b Results in Upregulated SELP Expression}

Similar to the findings in septic platelets, miR-26b was significantly downregulated in MEG-01 cells in response to LPS (Figure 5D). These findings suggested that sepsis could trigger MKs to alter miRNA levels as well. Although there were some former pieces of evidence that miR-26b regulates SELP expression in hyperglycemia [26], we wanted to confirm the functional relationship between miR-26b and SELP mRNA under inflammatory conditions. As LPS resulted in a lowered miR-26 level in MEG-01 cells, we here applied specific miRNA mimics to artificially overexpress this miRNA in order to investigate the change in SELP expression (Figure 5E). We found that highly elevated miR-26b expression reduced the level of SELP mRNA in MEG-01 cells, with about 50\% compared to those samples treated with NEG-01 mimic (Figure 5F). Of note, this manipulation did not alter the expression of other miRNAs, such as miR-223 (not shown). These data underlined the fact that miR-26b targeted $S E L P$, and decreased miR-26b contributed to elevated SELP expression of MKs and platelets in sepsis.

\subsection{Decreased Dicer1 Level in Platelets and MKs Results in Abnormal miRNA Among Septic Conditions}

We next focused on the mechanism via mature miRNAs that were dysregulated in sepsis. Alteration of the Dicer1 level was first analyzed by Western blotting in septic vs. control platelets. There was a significantly lower Dicer1 protein level in platelet lysates of septic individuals (Figure 6A). Similarly, LPS-stimulated MEG-01 cells showed decreased protein expression of Dicer1 than control samples detected by fluorescence microscopy (Figure 6B,C).

We then applied two additional approaches to further investigate the direct effect of abnormal Dicer level on miRNA in sepsis: i) by silencing of DICER1 expression using siRNA to mimic sepsis-reduced Dicer function in MEG-01 cells and ii) via specific inhibition of calpain 1 and calpain 2 with calpeptin to modulate the level of miR-26b in these cells. For this purpose, we transfected MEG-01 cells with Dicer1 specific siRNA for $24 \mathrm{~h}$ to downregulate DICER1 expression. The efficacy of transfection was confirmed via the quantification of the Dicer1 siRNA level, showing highly elevated expression (Figure 7A). This manipulation resulted in lowered DICER1 mRNA vs. control samples with NEG-01 siRNA (Figure 7B). As a consequence, miR-26b was significantly decreased $(p<0.05)$ (Figure $7 C$ ), while SELP mRNA level was upregulated $(p<0.05)$ (Figure 7E). In parallel, we also analyzed the expression of Dicer1-independent miR-451 to check the specificity of this intervention, and no change was seen in this miRNA (Figure 7D). To test the role of lower Dicer activity on decreased platelet miRNAs, additional experiments were performed when calpeptin inhibited the calpain function induced by increased intracellular $\mathrm{Ca}^{2+}$ concentration upon LPS or TNF- $\alpha$-triggered signaling [28]. When calpain function was blocked, and the cleavage of Dicer was prevented by calpeptin in the presence of LPS (Figure 7F) or TNF- $\alpha$ (data not shown), the mature miR-26b level was restored in MEG-01 cells. These data supported our hypothesis that abnormal Dicer activity in sepsis could reduce miR-26b in both platelets and MKs. 

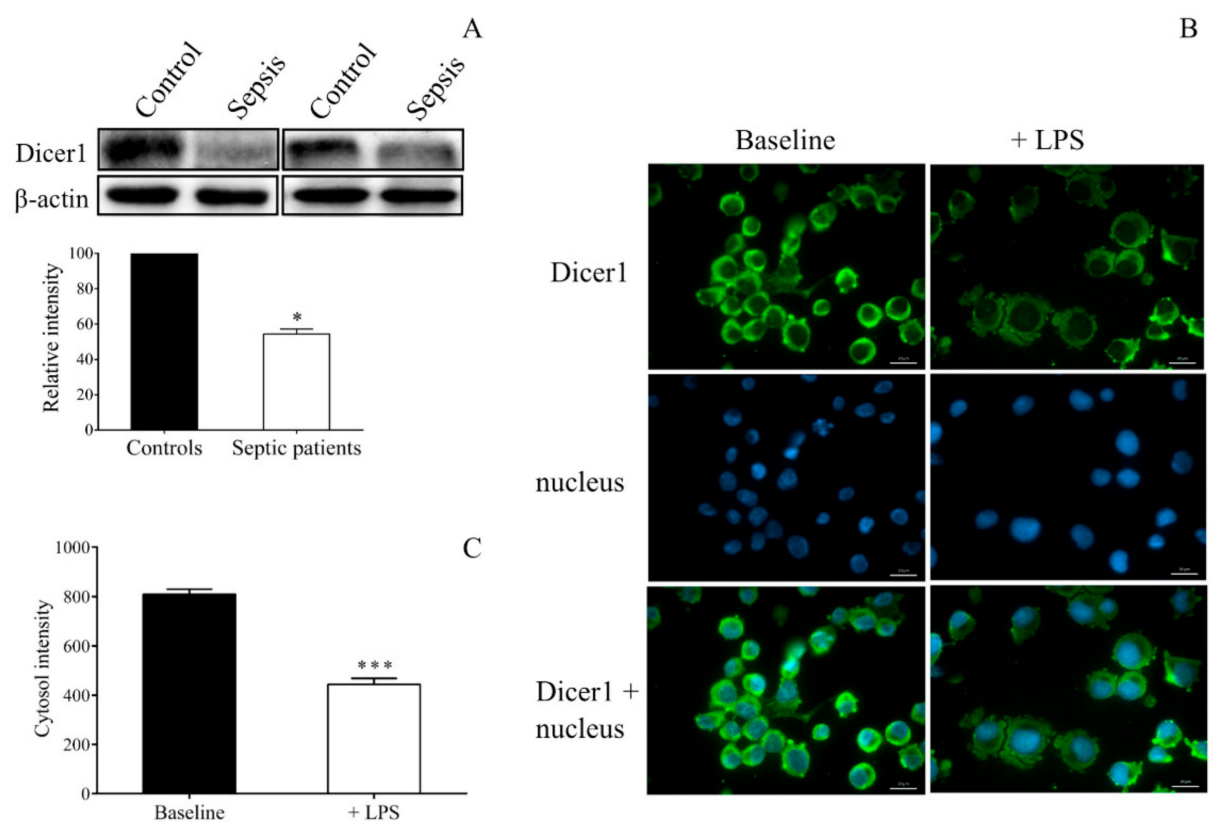

Figure 6. Investigation of Dicer1 level in septic platelets and LPS-stimulated MEG-01 cells in regard to altered miRNAs. First, septic platelets $(n=5)$ within $24 \mathrm{~h}$ of the onset of sepsis were studied for the Dicer1 protein level by Western blotting (A). We found a significantly lower expression of Dicer1 in septic platelets. LPS-stimulated MEG-01 cell cultures were intracellularly analyzed for Dicer1 positivity with a fluorescence microscope, showing decreased intensity after LPS treatment (B). Fluorescence intensity of Dicer1 immunostaining in the cytosol was analyzed $(n=15 /$ experiment) (C). Green: Dicer1 staining; blue: cell nuclei. Scale bar: $20 \mu \mathrm{m}$. Mean \pm SEM was depicted, ${ }^{*} p<0.05,{ }^{* * *} p<0.001$ based on statistical analyses. 

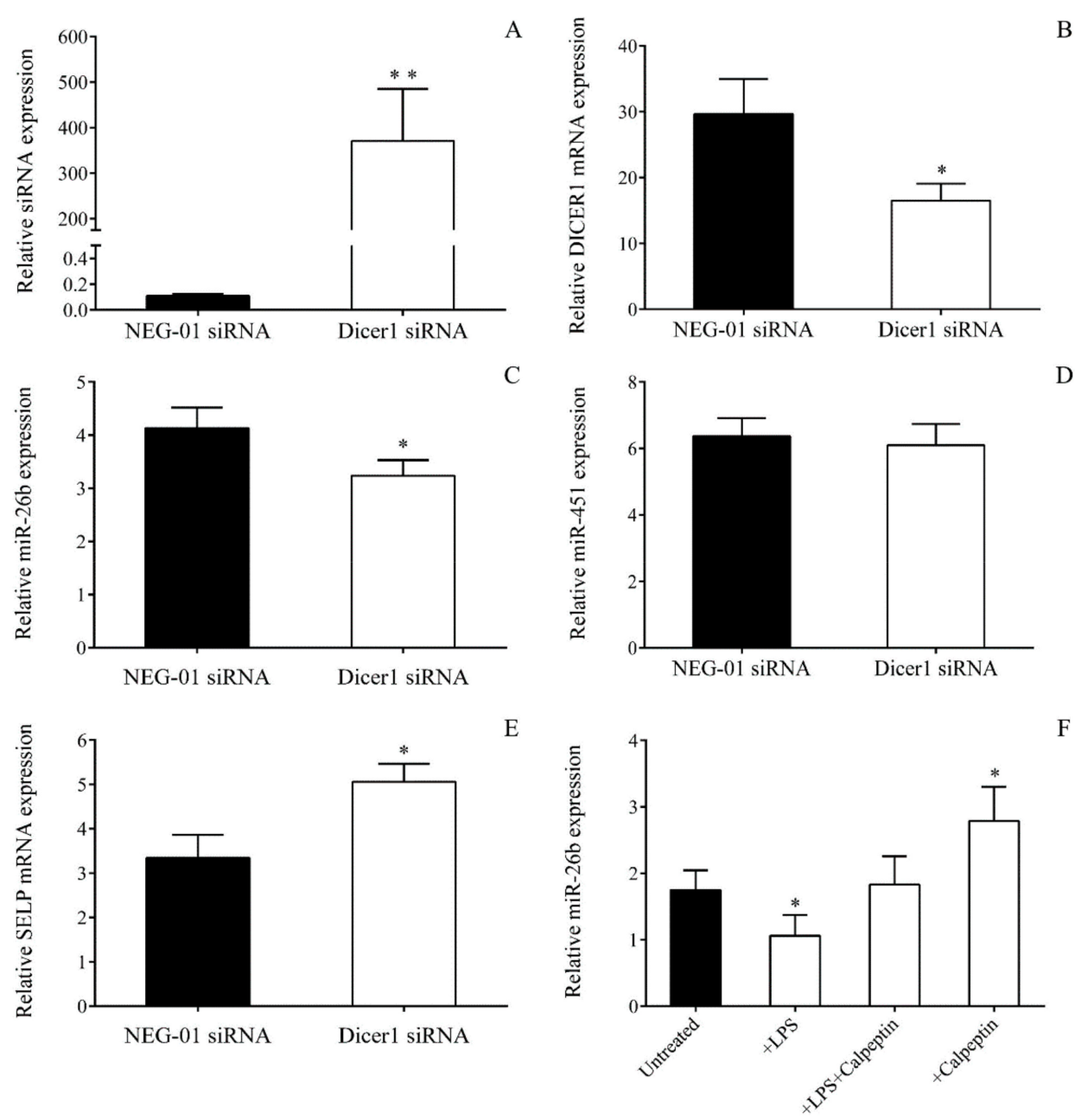

Figure 7. Investigation of the functional role of Dicer enzyme in attenuated miRNA levels in sepsis. First, to mimic sepsis-induced alteration of the Dicer1 level, DICER1 expression was downregulated via siRNA transfection in MEG-01 cells for the analysis of miR-26b and its target SELP mRNA. Dicer1 specific siRNA was successfully transfected into MK cell cultures based on the highly elevated level of Dicer1 siRNA measured by RT-qPCR (A). This resulted in decreased DICER1 mRNA expression compared to control samples with NEG-01 siRNA (B). In these cells, reduced miR-26b (C) with elevated SELP mRNA levels were quantified (E). In addition, Dicer1-independent miR-451 (D) was analyzed to double-check the specificity of siRNA transfection that showed no change due to manipulation. Second, calpain inhibition was applied to alter miRNA levels in MEG-01 cells among inflammatory conditions in vitro. Calpeptin significantly restored miR-26b (F) levels when was used during LPS treatment, suggesting the role of abnormal Dicer function in miRNA expression of sepsis. Mean \pm SEM was depicted ( $n=4-6 /$ experiment). ${ }^{*} p<0.05,{ }^{* *} p<0.01$ vs. NEG-01 or untreated samples based on statistical analyses.

\section{Discussion}

TLR4 receptor is functional on both platelets and MKs [12]. In sepsis, platelets can be stimulated by LPS via TLR4, resulting in primed platelet activation elicited by other agonists [29,30]. Hence, there is a key role of the TLR4 receptor in the modulation of platelet phenotype in sepsis $[13,27]$. On the other hand, severe inflammation via TLR2 also regulates MK function that affects platelet production and function with enhanced GPIb and COX-2 protein expression [14]; however, no data has been published about TLR4 in this context. In former animal models, when mice were exposed to a sublethal/low dose of LPS for up to 1 week, platelets became gradually activated, showing high P-selectin surface positivity and a larger sensitivity to aggregation as a reflection to the action of 
LPS on MKs [31,32]. Very recently, ITGA2B (integrin subunit $\alpha \mathrm{IIb}$ ) expression has been found to be upregulated in circulating platelets during sepsis via dynamic trafficking of specific mRNA from MKs, and this was accompanied by increased production of integrin subunit $\alpha \mathrm{Ill} b$ and activation of integrin $\alpha \mathrm{IIb} \beta 3$ [22]. All these changes in MKs may provide a pro-thrombotic phenotype of platelets in sepsis that could affect the procoagulant activity of the blood with increased risk for thrombosis [27]. Of note, there was no former data on how platelet P-selectin expression can be regulated via the MK-platelet axis during sepsis.

Recently, the potential role of miRNAs in platelet and MK function has also got in focus [25,33]. For instance, platelet miR-27b can regulate platelet synthesis of trombospondin-1 [19], or miR-15a modulates GPVI-mediated $\alpha \mathrm{IIb} \beta 3$ activation and $\alpha$-granule release in MKs [34]. In sepsis, there was only one former publication, which reported impaired miRNA levels in exosomes and pooled human blood cells but not in platelets [35]. Since leukocytes and platelets consist of the different repertoire of miRNAs [36], here we sought to investigate the miRNA profile of purified platelets of septic patients.

First, we profiled miRNA expression in randomly selected platelet samples from three septic patients by TaqMan Open Array. In comparison to normal individuals, 121 downregulated and 61 upregulated miRNAs were found in the septic platelets vs. controls. In the entire sepsis group consisting of 21 patients showing an increased level of platelet activation, we validated the expression of platelet miR-26b that regulates SELP expression [26]. This platelet miRNA showed significantly reduced levels than normal. Highly attenuated levels of platelet miR-26b were associated with the development of septic shock and early death. Accordingly, this platelet miRNA might act as a reliable biomarker for indicating platelet reactivity in this disease, as miRNAs have been recently suggested for such clinical reasons $[37,38]$. Similar to intracellular miRNA expression, reduced levels of its circulating form have been effectively used as laboratory biomarkers in serum samples of septic shock subjects [35]. In addition, the level of miR-199b in peripheral blood cells correlates with disease severity, while exosomal miR-125b predicts survival in sepsis [35].

Septic platelets demonstrated augmented SELP mRNA level compared to controls in the presence of elevated IL1B expression that was earlier described in septic platelets [20]. Importantly, when we further analyzed SELP expression based on the values of MPV, higher SELP mRNA levels were found in those with platelets having larger MPV values ( $\geq 11.1 \mathrm{fL}$ ). There is a large number of papers reporting MPV as a measure of platelet size and activity as well [24]. Higher MPV has been associated with various disease conditions, for example, in patients with acute coronary syndrome [24]. Larger platelets usually contain more secretory granules, more RNA, and thus become more reactive than their smaller counterparts [39]. Although SELP expression did not significantly correlate with the outcome of sepsis in these patients, increased MPV values also predicted disease prognosis, as reported by others in sepsis with pneumonia [40]. In the presence of an augmented mRNA level that predicts changes in protein expression, higher P-selectin concentration was detected in platelet lysates after $72 \mathrm{~h}$ of sepsis onset that could be a result of altered miRNA and mRNA levels in platelets and MKs. Based on a recent animal model with peritoneal sepsis, mice showed increased P-selectin positivity at $48 \mathrm{~h}$ as a part of the prothrombotic phenotype of platelets developed in sepsis [41]. Increased P-selectin expression on activated platelets is highly involved in the formation of heterotypic aggregates, resulting in microvascular thrombosis [9]. The blockade of platelet P-selectin, in combination with simultaneous inhibition of $\mathrm{CD} 11 \mathrm{~b}$ receptor, on neutrophils effectively attenuates platelet-neutrophil interactions in septic shock [42]. Thus, enhanced SELP expression in platelets might contribute to a higher risk for cellular interactions and might represent a new therapeutic target in those with sepsis.

We started from some evidence that MKs are also affected by sepsis that results in altered mRNA levels in circulating platelets [22,43]. Hence, we thoroughly investigated LPS-induced transcriptional changes in MEG-01 cell cultures since increased ITGA2B mRNA content has been observed in MKs to be invested in platelets during sepsis [22]. For this purpose, we stimulated MEG-01 cell cultures with LPS for $4 \mathrm{~h}$ to analyze the transcriptome of MKs. LPS could induce the activation of the NF- $\mathrm{kB}$ pathway in MEG-01 cells, as earlier observed via TLR2 signaling [14], that we visualized with the enhanced nuclear 
translocation of p65 by fluorescence microscopy. Using RNA-seq, 1060 significantly downregulated and 354 upregulated transcripts were detected in LPS-activated MKs. Based on this analysis, SELP was identified among the top 25 most upregulated genes. We then validated the expression of SELP in LPS-stimulated MEG-01 cells, showing a significant elevation. To compare our data with recently published results in sepsis [22], the expression of ITGA2B was also analyzed in our septic platelets and LPS-activated MK cell cultures by RT-qPCR, which were upregulated vs. controls (not shown). These results revealed that there must occur substantial alterations in the MK transcriptome after the onset of sepsis. Modulated RNA expression might result in transcriptional and translational events via the trafficking of RNA content through the MK-platelet axis that was found in the background of increased integrin subunit $\alpha \mathrm{IIb}$ and granzyme B production in septic platelets $[22,43]$.

In LPS-stimulated MEG-01 cell samples, miR-26b was downregulated, similar to ex vivo septic platelets. In type 2 diabetes mellitus, decreased platelet miR-26b has been associated with elevated SELP expression, resulting in higher platelet reactivity [26]. In contrast, after cardiopulmonary bypass, overexpression of platelet miR-10b and miR-96 decreases mRNAs of GPIb and VAMP8, as well as their protein levels, causing defected platelet function [44]. The modulatory effect of miR-26b on SELP expression was confirmed in MEG-01 cells under these inflammatory conditions using a specific miRNA mimic, suggesting that sepsis-reduced miR-26b caused increased SELP expression in sepsis.

Abnormal Dicer1 activity has been found to be an important factor in dysregulated miRNAs that have been revealed in Dicer1-deficient murine platelets [18] and in diabetic platelets, showing decreased Dicer function [26,45]. Dicer enzyme is a substrate of calpain 1 ( $\mu$-calpain) and calpain 2 (m-calpain), which can be found in platelets [45]. In sepsis, there was no data about how the Dicer function modulates miRNA expression. We here observed decreased Dicer1 levels in platelet lysates of septic individuals. Similarly, LPS-stimulated MEG-01 cells showed decreased Dicer1 expression. Direct investigation of Dicer1 function with its gene silencing by siRNA and through specific inhibition of calpain 1 and calpain 2 with calpeptin to modulate miRNAs in MEG-01 cells revealed that abnormal Dicer1 activity was generated in sepsis that could reduce miR-26b and, in turn, to elevate SELP expression in both platelets and MKs. Accordingly, elevated intracellular $\mathrm{Ca}^{2+}$ concentration in response to LPS or TNF- $\alpha$ induces calpain function that cleaves the Dicer enzyme, causing less mature miRNAs [28]. When the function of calpain 1 and 2 was blocked, and the cleavage of Dicer was prevented by calpeptin in the presence of any of these inflammatory mediators, mature miR-26b levels were restored in MEG-01 cells. Accordingly, changes in Dicer activity due to sepsis might occur in both platelets and MKs, shaping the profile of miRNAs. Based on these current results, we proposed a signaling axis in MKs and platelets upon sepsis when lower Dicer level resulted in decreased miR-26b with elevated target SELP expression that could contribute to the elevated level of platelet activation status.

Finally, we extended our study with a GO analysis. Upregulated SELP seemed to be involved in seven different pathways of MKs in TLR4 involvement, such as in the regulation of inflammatory response. High SELP expression in peripheral blood cells has been investigated as a new risk factor in rheumatoid arthritis [46], and some specific haplotypes of SELP gene have been related to a higher risk for myocardial infarction [47], but no former data of altered SELP expression were available in regard to platelet/MK function in sepsis. According to these current data, SELP might play a central role via inflammatory signaling of MKs by LPS apart from encoding a key cellular adhesion molecule P-selectin.

There were some limitations to this study. First, a limited number of septic patients could be involved in this study due to the strict criteria of enrollment. Second, we did not investigate the role of other LPS-independent mechanisms of altered platelet miRNA expression upon sepsis. Hence, further studies are required to examine the details of this complex mechanism.

In conclusion, septic platelets showed an altered miRNA profile with 182 abnormally expressed miRNAs via TLR4. Reduced platelet miR-26b correlated with sepsis severity and mortality; thus, it might become a useful biomarker for indicating elevated platelet activation status in this disease. 
Upregulated SELP expression in MKs through TLR4 resulted in enhanced P-selectin expression in platelets and might be also involved in shaping inflammatory responses of MKs.

\section{Materials and Methods}

\subsection{Study Design, Participants, and Blood Sample Preparation}

In this analyst-blinded, case-control study 21 patients with a primary diagnosis of sepsis (16 males, 5 females, aged 64 (51-70) years) were prospectively included into this study within $24 \mathrm{~h}$ of admission to the intensive care unit (ICU) of one of the three clinical departments (Table 1). Sepsis was diagnosed based on the criteria of the American College of Chest Physicians/Society of Critical Care Medicine Consensus, which defined systemic infection and 2 of the following: (a) temperature $>38^{\circ} \mathrm{C}$ or $<36{ }^{\circ} \mathrm{C}$; (b) heart rate $>90$ beats/min; (c) respiratory rate $>20$ breaths/min or $\mathrm{PaCO}_{2}<32 \mathrm{~mm} \mathrm{Hg}$; (d) WBC count $>12,000 / \mathrm{mm}^{3},<4000 / \mathrm{mm}^{3}$, or $>10 \%$ bands [48]. The sequential organ failure assessment (SOFA) score was determined by the clinicians, and the administration of any antiplatelet agents was recorded in each case. Exclusion criteria for enrollment included malignancy, autoimmune disease, pregnancy, severe thrombocytopenia, and acute myocardial infarction or acute ischemic stroke within 1 month. All-cause 28-day mortality was recorded prospectively.

To investigate platelet miRNAs and mRNA levels in sepsis, venous blood samples were obtained from patients by atraumatic venipuncture into Vacutainer ${ }^{\circledR}$ tubes containing $0.105 \mathrm{M}$ sodium citrate (Becton Dickinson, San Jose, CA, USA). Samples were prepared within $60 \mathrm{~min}$ after sampling and were centrifuged at $170 \times g$ for $15 \mathrm{~min}$ at room temperature (RT) to obtain platelet-rich plasma (PRP). The upper layer of PRP was carefully transferred to a plastic tube to avoid any leukocyte contamination. In the case of 7 septic patients, follow-up samples were also obtained after $72 \mathrm{~h}$ of sepsis onset.

In parallel, 21 age- and gender-matched controls (14 males, 7 females, aged 58 (42-65) years) were enrolled among volunteers or staff members from the Departments of Laboratory Medicine and Internal Medicine who underwent a detailed medical history, physical examination, and routine laboratory tests and were free of acute cardiovascular, metabolic, inflammatory diseases, or cancer (Table 1). All participants gave written informed consent. The study was approved by the Ethics Committee of the University of Debrecen (permit number: 4780-2017) in accordance with the Declaration of Helsinki.

\subsection{Leukocyte-Depleted Platelet Preparation}

Leukocyte-depleted platelet samples (LDP) were purified by anti-CD45-conjugated magnetic microbeads (Dynabeads ${ }^{\circledR}$, Invitrogen, Oslo, Norway) within $30 \mathrm{~min}$ of blood sampling, as we previously described from our laboratory [26]. Briefly, after the incubation of $2 \mathrm{~mL}$ PRP with the beads for $30 \mathrm{~min}$ at RT, samples were inserted into a magnetic separator (Becton Dickinson, San Jose, CA, USA) for $2 \times$ $2 \mathrm{~min}$, and LDP was then transferred into a fresh tube for additional centrifugation $(1500 \times g, 15 \mathrm{~min}$, RT). Platelet pellet was lysed with $750 \mu \mathrm{L}$ TRI reagent (Molecular Research Center Inc, Cincinnati, $\mathrm{OH}, \mathrm{USA}$ ) and stored at $-20^{\circ} \mathrm{C}$ before RNA isolation.

\subsection{Total RNA Extraction}

Total RNA from LDP and MK cell culture samples was isolated by TRI reagent according to the manufacturer's recommendations. The purity and the concentration of separated RNA samples were verified by a NanoDrop 2000 spectrophotometer (Thermo Scientific, Wilmington, DE, USA). Total RNA samples were stored at $-80^{\circ} \mathrm{C}$.

\subsection{TaqMan Open Array-Based miRNA Profiling in Septic Platelets}

First, we randomly selected 3 total RNA samples from the septic and control groups, and we analyzed 754 types of miRNA using a TaqMan Open Array technology (Applied Biosystems, Foster City, CA, USA) following the manufacturer's protocol. Briefly, 100 ng of total RNA was used for reverse transcription with TaqMan MicroRNA Reverse Transcription Kit (Applied Biosystems, 
Foster City, CA, USA) and Megaplex RT Primers Human Pool Set v3.0 (Applied Biosystems, Foster City, CA, USA). The reactions were performed for 40 cycles of $16^{\circ} \mathrm{C}$ for $2 \mathrm{~min}, 42^{\circ} \mathrm{C}$ for $1 \mathrm{~min}, 50^{\circ} \mathrm{C}$ for $1 \mathrm{~s}$, and 1 cycle of $85^{\circ} \mathrm{C}$ for $5 \mathrm{~min}$. Then, specific complementary DNA (cDNA) samples were pre-amplified with Megaplex PreAmp Primers Human Pool Set v3.0, as well as TaqMan PreAmp Master Mix (Applied Biosystems, Foster City, CA, USA), to increase the quantity of the desired cDNA. PCR reactions were run at the following conditions: $95^{\circ} \mathrm{C}$ for $10 \mathrm{~min}, 55^{\circ} \mathrm{C}$ for $2 \mathrm{~min}, 72{ }^{\circ} \mathrm{C}$ for $2 \mathrm{~min}$, and 12 cycles of $95^{\circ} \mathrm{C}$ for $15 \mathrm{~s}$ and $60^{\circ} \mathrm{C}$ for $4 \mathrm{~min}$. Diluted pre-amplification products (1:40) and PCR reaction mix containing TaqMan Open Array Real-Time PCR Master Mix (Applied Biosystems, Foster City, CA, USA) were transferred into a 384-well plate, and the Open Array AccuFill system loaded the samples to the prepared TaqMan Open Array Human MicroRNA panels (Applied Biosystems, Foster City, CA, USA). Finally, plates were run on a QuantStudio 12 K Flex qPCR instrument (Applied Biosystems, Foster City, CA, USA). For data normalization, the RNU-48 control assay was used in this experiment. Data were analyzed with Thermo Fisher Cloud System (Thermo Fischer Scientific, Waltham, MA USA) and Expression Suite Software v1.0.3 (Applied Biosystems, Foster City, CA, USA).

\section{5. miRNA Specific Stem-Loop RT-qPCR Analysis}

The expression of selected platelet miRNAs in the entire study groups was validated by miRNA specific Universal ProbeLibrary (UPL)-probe based stem-loop RT-qPCR method [26]. Briefly, this quantification technique included two steps: (1) miRNAs (input total RNA: $10 \mathrm{ng}$ ) were transcribed into cDNA via reverse transcription using miRNA-specific stem loop-RT primer ( $500 \mathrm{nM}$, Integrated DNA Technologies, Leuven, Belgium) and TaqMan ${ }^{\circledR}$ MicroRNA Reverse Transcription Kit (Applied Biosystems, Foster City, CA, USA) and (2) miRNA quantification was performed by RT-qPCR using designed universal reverse primer (100 $\mu \mathrm{M}$, Sigma-Aldrich, St. Louis, MO, USA), miRNA-specific forward primer (100 $\mu \mathrm{M}$, Integrated DNA Technologies, Leuven, Belgium), and UPL probe \#21 (10 $\mu \mathrm{M}$, Roche Diagnostics, Mannheim, Germany) with Taq polymerase ( $5 \mathrm{U} / \mu \mathrm{L}$, Thermo Scientific, Wilmington, DE, USA) and dNTPs ( $2.5 \mathrm{mM}$, Thermo Scientific). The reactions were pre-incubated at $95^{\circ} \mathrm{C}$ for 1 min, followed by 40 cycles of $95^{\circ} \mathrm{C}$ for $15 \mathrm{~s}$ and $60^{\circ} \mathrm{C}$ for $30 \mathrm{~s}$. All the measurements were conducted in triplicate on a QuantStudio $12 \mathrm{~K}$ Flex qPCR instrument (Applied Biosystems, Foster City, CA, USA). For normalization, the small-nucleolar RNU- 43 was measured as a reference gene, similarly used in our former study [26]. Primers and qPCR assays were designed by the software developed by Czimmerer et al. [49], and oligonucleotides that were used in this study are listed in Supplementary Table S3.

\section{6. mRNA Specific RT-qPCR Analysis}

Complementary DNA (cDNA) synthesis was performed with a High Capacity cDNA Reverse Transcription kit (Applied Biosystems, Foster City, CA, USA) according to the manufacturer's recommendation. The initial amount of RNA in LDP was $200 \mathrm{ng}$ per reaction, while $1000 \mathrm{ng}$ per reaction was used in the MK experiments. Quantitative PCR was performed on a QuantStudio $12 \mathrm{~K}$ Flex qPCR instrument (Applied Biosystems, Foster City, CA, USA) with Light Cycler 480 SYBR Green I Master mix (Roche Diagnostics, Mannheim, Germany) and gene-specific primers (10 $\mu \mathrm{M}$, Integrated DNA Technologies, Leuven, Belgium). The reactions were incubated at $95{ }^{\circ} \mathrm{C}$ for $10 \mathrm{~min}$, followed by 40 cycles of $95^{\circ} \mathrm{C}$ for $10 \mathrm{sec}$ and $60^{\circ} \mathrm{C}$ for $1 \mathrm{~min}$. For normalization, we used the reference gene RPLP0 (36B4). Sequences of the primers for mRNAs are also listed in Supplementary Table S3.

\subsection{In Vitro Activation of Normal Human Platelets by LPS}

LDP samples prepared from specimens of 5 healthy volunteers were treated with vehicle (PBS) or LPS (O55:B5, $100 \mathrm{ng} / \mathrm{mL}$, Sigma-Aldrich, St. Louis, MO, USA) in the presence of lipoprotein binding protein (LBP, $100 \mathrm{ng} / \mathrm{mL}$, Sigma-Aldrich, St. Louis, MO, USA) and soluble CD14 (150 ng/mL, Sigma-Aldrich, St. Louis, MO, USA) at $37^{\circ} \mathrm{C}$ for $4 \mathrm{~h}$, as formerly described by others [20]. For positive control, tumor necrosis factor- $\alpha$ (TNF- $\alpha)(100 \mathrm{ng} / \mathrm{mL}$, Gibco, Grand Island, NY, USA) was used as a key pro-inflammatory mediator expressed upon TLR4 activation. Platelets were then centrifuged (1500 g, 
$15 \mathrm{~min}, \mathrm{RT}$ ), and platelet pellet was lysed with $750 \mu \mathrm{L}$ TRI reagent and stored at $-20{ }^{\circ} \mathrm{C}$ before RNA isolation. To evidence the activation of the TLR4 pathway in platelets by LPS, IL1B mRNA level was quantified in parallel to SELP expression by RT-qPCR.

\subsection{Culturing of MEG-01 Cells Mimicking Septic Conditions}

Human megakaryoblastic leukemia cell line MEG-01 cells (Sigma-Aldrich, St. Louis, MO, USA) were cultured in RPMI-1640 medium (Sigma-Aldrich, St. Louis, MO, USA) with 10\% fetal bovine serum (FBS, Sigma-Aldrich, St. Louis, MO, USA), $100 \mathrm{U} / \mathrm{mL}$ Penicillin, and $100 \mu \mathrm{g} / \mathrm{mL}$ Streptomycin (Sigma-Aldrich, St. Louis, MO, USA) at $37^{\circ} \mathrm{C}, 5 \% \mathrm{CO}_{2}$. The cell count was set to $0.3 \times 10^{6} / \mathrm{mL}$, similar to our recent study [26]. MKs were stimulated with LPS (O55:B5, $100 \mathrm{ng} / \mathrm{mL}$, Sigma-Aldrich, St. Louis, MO, USA) in the presence of LBP (100 ng/mL, Sigma-Aldrich, St. Louis, MO, USA) and soluble CD14 (150 ng/mL, Sigma-Aldrich, St. Louis, MO, USA) for 4-24 h to maintain them under in vitro 'septic' conditions as applied for the analysis of sepsis-induced platelet activation [20]. In positive control samples, MEG-01 cells were treated with TNF- $\alpha$ (100 ng/mL, Gibco, Grand Island, NY, USA), while negative control samples were cultured with vehicle (PBS). After treatment, cells were washed once with sterile PBS, then lysed in $750 \mu \mathrm{L}$ TRI reagent, and stored at $-20^{\circ} \mathrm{C}$ before RNA isolation. To demonstrate the inflammation specific activation of MEG-01 cells via the NF-kB pathway, IL1B expression was analyzed by RT-qPCR.

\subsection{RNA-Sequencing}

To obtain global transcriptome data of LPS-stimulated MKs, high throughput mRNA sequencing analysis was performed on Illumina Sequencing Platform (Illumina, San Diego, CA, USA). For this purpose, 3 sets of MEG- 01 cells $\left(0.3 \times 10^{6} \mathrm{cell} / \mathrm{mL}\right)$ were cultured in the presence of LPS or vehicle for $4 \mathrm{~h}$, as described above. Total RNA was extracted and quantified, and RNA sample quality was checked on Agilent BioAnalyzer using Eukaryotic Total RNA Nano Kit (Agilent Technologies, Santa Clara, CA, USA) according to the manufacturer's protocol. Samples with RNA integrity number (RIN) value $>7$ were accepted for the library preparation process.

RNA-Seq libraries were prepared from total RNA (200 ng) using NEBNext ${ }^{\circledR}$ Ultra II RNA Sample Preparation Kit for Illumina (New England BioLabs, Ipswich, MA, USA) according to the manufacturer's protocol. Briefly, poly-A tailed RNAs were purified by oligodT-conjugated magnetic beads and fragmented at $94{ }^{\circ} \mathrm{C}$ for $15 \mathrm{~min}$. First-strand cDNA was generated by random priming reverse transcription, and the second strand synthesis step was performed to generate double-stranded cDNA. After the repairing ends and adapter ligation steps, adapter-ligated fragments were amplified in enrichment PCR, and, finally, sequencing libraries were generated. The sequencing run was executed on Illumina NextSeq500 instrument (Illumina) using single-end 75 cycles sequencing. Aligned sequencing data were deposited into the NCBI SRA database under accession no. PRJNA587604.

\subsection{Analysis of RNA-Seq Data}

Raw sequencing data (fastq) was aligned to the human reference genome version GRCh37 using the HISAT2 algorithm, and BAM files were generated. Downstream analysis was performed using StrandNGS software (www.strand-ngs.com). BAM files were imported into the software, and the DESeq1 algorithm was used for normalization. To identify differentially expressed genes between untreated and LPS-stimulated conditions, ANOVA with Tukey post hoc test was used. Heatmaps and dot plots were drawn using R packages pheatmap and ggplot2.

\subsection{Gene Ontology Analysis}

Lists of differentially expressed genes were analyzed using the Panther tool (http://www. geneontology.org/) and the GO enrichment analysis function to create a GO. GOs with fold enrichment $\geq 2$ and $p$-value $<0.05$ were selected, and results were presented according to their $-\log _{10} p$-value. The bar graph was drawn using the R package ggplot 2 . 


\subsection{Transfection of MEG-01 Cells with miR-26b Mimic}

MEG-01 cells pretreated with LPS or TNF- $\alpha(100 \mathrm{ng} / \mathrm{mL})$ for $4 \mathrm{~h}$ were centrifuged and resuspended in Opti-MEM I Reduced Serum Medium (Gibco, Grand Island, NY, USA) with 3\% FBS, 100 U/mL Penicillin, and $100 \mu \mathrm{g} / \mathrm{mL}$ Streptomycin. The overexpression of miRNAs was performed using mirVana ${ }^{\circledR}$ miR-26b mimic (40 pmol, Ambion, Austin, TX, USA) with Lipofectamine RNAiMAX ${ }^{\circledR}$ Transfection Reagent (Invitrogen, Carlsbad, CA, USA) for $24 \mathrm{~h}$ at $37{ }^{\circ} \mathrm{C}$ and $5 \% \mathrm{CO}_{2}$. In parallel, the negative control sample was treated with mirVana ${ }^{\circledR}$ miRNA mimic negative control (NEG-01, 40 pmol, Ambion, Austin, TX, USA). After transfection, total RNA was extracted, miR-26b expression was quantified with SELP mRNA, as described above.

\subsection{Western Blot}

Isolated platelets obtained from septic and control individuals were lysed in RIPA buffer containing a protease inhibitor mix (Sigma-Aldrich, St. Louis, MO, USA). Proteins were separated by electrophoresis using 7.5\% polyacrylamide gel and then transferred onto a nitrocellulose membrane (Bio-Rad, Hercules, CA, USA). After blocking with Tris-buffered saline/Tween (TBST; $20 \mathrm{mM}$ Tris, $140 \mathrm{mM} \mathrm{NaCl}, 0.1 \%$ (vol/vol) Tween 20) containing 5\% bovine serum albumin (BSA, Sigma-Aldrich, St. Louis, MO, USA) for 90 min at RT, membranes were incubated with monoclonal mouse anti-human Dicer1 (ab14601, 1:100, Abcam, Cambridge, UK) or monoclonal mouse anti-human P-selectin (sc-19672, 1:100, Santa Cruz Biotechnology, Dallas, TX, USA) antibody in TBST with $5 \%$ BSA at $4{ }^{\circ} \mathrm{C}$ for overnight with gentle agitation, respectively. Anti- $\beta$-actin antibody (ab8227, 1:1000, Abcam, Cambridge, $\mathrm{UK}$ ) was used to ensure equal protein concentrations in all lanes. Membranes were labeled with HRP-conjugated goat anti-mouse secondary antibody (1:100,000, Bio-Rad, Hercules, CA, USA) for $1 \mathrm{~h}$ at RT, and immunoreactivity was visualized by Immobilon Western Chemiluminescent HRP Substrate (Millipore, Billerica, MA, USA). The relative intensity of P-selectin or Dicer1 bands was determined in both septic and control samples by normalization to $\beta$-actin.

\subsection{Flow Cytometry}

Investigation of platelet activation level via surface P-selectin expression on platelets was performed, as previously reported [26]. Briefly, $40 \mu \mathrm{L}$ of whole blood samples were fixed in $1 \mathrm{~mL} 1 \%$ PFA and kept at RT for $1 \mathrm{~h}$. Platelets were identified by a FITC-conjugated monoclonal antibody to GPIX (CD42a-FITC, Becton Dickinson, San Jose, CA, USA). Platelet activation was detected by phycoerythrin (PE)-labeled anti-P-selectin (CD62-PE, Becton Dickinson, San Jose, CA, USA). Fixed platelets were incubated with saturating concentrations of antibodies for $20 \mathrm{~min}$ in the dark at RT. As a control for immunolabeling with anti-CD62 antibody, platelets were incubated with PE-coupled non-immune mouse $\mathrm{IgG}_{1}$ antibody (Becton Dickinson, San Jose, CA, USA). A total of 10,000 dual-color labeled platelet events were acquired on an FC-500 flow cytometer (Beckman Coulter, Pasadena, CA, USA). Results were expressed as the percentage of double-positive platelets.

\subsection{Fluorescence Microscopy}

Detection of NF-kB activation in MEG-01 cells was visualized via p65 nuclear staining based on our previous study [50] with some minor modifications. MEG-01 cells were cultured on 6-well plates for 2 days, were then treated with LPS or vehicle (PBS) for $4 \mathrm{~h}$, and were fixed with ice-cold methanol-acetone ( $50 \mathrm{v} / \mathrm{v} \%$ ) for $10 \mathrm{~min}$. These cells were transferred onto sterile uncoated microscope slides at a density of $5 \times 10^{4}$ cells/slide. Non-specific antibody binding sites were blocked with FBS (Sigma-Aldrich, St. Louis, MO, USA) for $15 \mathrm{~min}$. For primary labeling of NF-kB p65 subunit, polyclonal rabbit anti-human p65 antibody $(100 \mu \mathrm{g} / \mathrm{mL}$, Sigma-Aldrich, St. Louis, MO, USA) was used for $1 \mathrm{~h}$ followed by secondary staining with Alexa Fluor 488-conjugated goat-anti-rabbit IgG $(5 \mu \mathrm{g} / \mathrm{mL}$, Sigma-Aldrich, St. Louis, MO, USA) for $1 \mathrm{~h}$. 
The protein level of Dicer1 in MEG-01 cells was also studied by fluorescence microscopy. MEG-01 cells were treated with LPS or PBS for $24 \mathrm{~h}$, and fixed cells were stained by mouse anti-human Dicer1 antibody $(2 \mu \mathrm{g} / \mathrm{mL}$, Abcam, Cambridge, UK) followed by secondary staining with Alexa Fluor 488-conjugated goat anti-mouse IgG $(5 \mu \mathrm{g} / \mathrm{mL}$, Invitrogen, Carlsbad, CA, USA).

During both analyses, cell nuclei were labeled with Hoechst 33,342 (Invitrogen, Carlsbad, CA, USA), and samples were observed by Zeiss Axio Scope.A1 fluorescent microscope (HBO 100 lamp) (Carl Zeiss Microimaging $\mathrm{GmbH}$, Goettingen, Germany). DAPI: excitation 365 nm, emission BP 445/50 nm; fluorescein: excitation BP 470/40 nm, emission BP525/50 nm. Images were analyzed with ZEN 2012 v.1.1.0.0. software (Carl Zeiss Microscopy $\mathrm{GmbH}$, Goettingen, Germany). The ratio of nuclear and perinuclear fluorescence intensity was calculated for NF-kB p65 staining, while fluorescence intensity in the cytoplasm was determined for Dicer1 positivity. The specificity of immunostaining was checked by incubating the cells with the secondary antibody only, and no background staining was found.

\subsection{Downregulation of DICER1 Expression by siRNA Transfection in MEG-01 Cells}

To investigate whether abnormal Dicer1 function could markedly affect miR-26b levels of MKs in sepsis, DICER1 expression was first silenced by specific siRNA (40-80 pmoL, ID: S23756, Invitrogen, Carlsbad, CA, USA) in MEG-01 cells $\left(0.3 \times 10^{6} / \mathrm{mL}\right)$ for $24-48 \mathrm{~h}$ in comparison to control samples with NEG-01 siRNA (Silencer Select Negative control No.1, Invitrogen, Carlsbad, CA, USA) according to the manufacturer's recommendations. Total RNA was then isolated, and the efficacy of transfection was monitored via the quantification of the Dicer1 siRNA level by TaqMan siRNA assay (ID: S23756_asy, Invitrogen, Carlsbad, CA, USA). Expressions of miR-26b with Dicer-independent miR-451 and DICER1 with SELP mRNAs were subsequently measured by RT-qPCR after transfection.

\subsection{Analysis of Dicer Function on miRNA Level Through Calpain Inhibition in MEG-01 Cells Among Inflammatory Conditions}

To examine the contribution of calpain substrate Dicer enzyme in the generation of altered miRNA levels in sepsis, we applied a MK model for sepsis-induced Dicer dysfunction in which 0.3 $\times 10^{6} / \mathrm{mL}$ MEG-01 cells were treated by a specific exogenous calpain 1 and 2 inhibitor, calpeptin ( $40 \mu \mathrm{mol} / \mathrm{L}$, Sigma-Aldrich, St. Louis, MO, USA) for $24 \mathrm{~h}$ in a similar way as it was performed previously [21,40]. The effect of calpeptin on miRNA expression was assessed in the following settings: vehicle (DMSO); LPS or TNF- $\alpha$; LPS or TNF- $\alpha$, together with calpeptin; calpeptin alone as a positive control. After treatment, total RNA was extracted, and miR-26b levels were measured by RT-qPCR, as described above.

\subsection{Other Laboratory Assays}

White blood cell (WBC) count and platelet count with MPV were determined by Advia 2120 Hematology System (Bayer Diagnostics, Tarrytown, NJ, USA). Serum C-reactive protein (CRP) and procalcitonin (PCT) levels were measured by electro-chemiluminescent immunoassay using a Cobas 8000 analyzer (Roche Diagnostics, Mannheim, Germany). Soluble P-selectin concentrations were determined in 10 randomly selected plasma samples from each study cohort by commercially available ELISA kit (R\&D Systems, Minneapolis, MN, USA) according to the manufacturer's instructions. Before performing this analysis, samples were thawed and then centrifuged at 10,000 $\mathrm{g}$ for $1 \mathrm{~min}$.

\subsection{Data Presentation and Statistical Analyses}

Data were expressed in the median with (IQR, interquartile range), or mean \pm standard deviation (SD), or standard error of the mean (SEM), as appropriate. A comparison of multiple groups was performed using ANOVA or Kruskal-Wallis with post hoc test, while t-test or Mann-Whitney U test and Chi-squared test were performed to compare two groups of data. The Kolmogorov-Smirnov test was used for the evaluation of the normality of the data. $p<0.05$ probability level was regarded as 
statistically significant. Analyses were performed using GraphPad Prism, version 6.01 (GraphPad Software, La Jolla, CA, USA).

Supplementary Materials: Supplementary Materials can be found at http://www.mdpi.com/1422-0067/21/3/866/s1. Table S1: List of miRNAs, which are differently expressed in platelets from patients with sepsis as compared to control donors; Table S2: List of genes, which are significantly upregulated or downregulated in MEG-01 cells in response to LPS analyzed by RNA-seq, Table S3: Sequences of primers for the analysis of mature miRNAs and mRNAs. In case of stem-loop RT primers, miRNA-specific sequences are highlighted in red.; Figure S1: Analysis of in vitro stimulated normal platelets by LPS via miR-26b (A), SELP (B) and IL1B (C) expression.; Figure S2: GO pathway enrichment analysis on differentially expressed genes in response to TLR4 activation in MEG-01 cells.

Author Contributions: Conceptualization, B.N.J.; methodology, Z.F., Z.C., S.P., B.N.J.; software, S.P., A.P.; validation, Z.C., F.F., B.N.J.; formal analysis, Z.F.; investigation, B.S., Z.F., M.P., F.F., Á.R.; resources, B.N.J.; data curation, G.N., G.K., M.B., I.S.; writing—original draft preparation, B.N.J.; writing—review and editing, J.K., S.P.K., B.N.J.; visualization, A.P.; supervision, B.N.J., S.P.K., J.K.; project administration, B.S., Z.F.; funding acquisition, B.N.J., J.K. All authors have read and agreed to the published version of the manuscript.

Funding: This research was funded by the GINOP-2.3.2-15-2016-00043 project. The project is co-financed by the European Union and the European Reginal Development Fund.

Acknowledgments: B.N.J. was a recipient of the Lajos Szodoray Grant and an OTKA Bridging Fund (General Medicine Faculty of University of Debrecen). B.S. was supported by the EFOP-3.6.1-16-2016-00022 Debrecen Venture Catapult program. Z.F. was supported by the ÚNKP-17-3 New National Excellence Program of the Ministry of Human Capacities. Z.C. is supported by the Premium Postdoctoral Fellowship Program of the Hungarian Academy of Sciences and the Hungarian Scientific Research Found (OTKA FK132185). The authors would like to thank Prof. Laszlo Nagy (Johns Hopkins University School of Medicine, St. Petersburg, FL, USA) for excellent technical advice and expertise on the NGS approaches.

Conflicts of Interest: The authors declare no conflict of interest. The funders had no role in the design of the study; in the collection, analyses, or interpretation of data; in the writing of the manuscript, or in the decision to publish the results.

\section{Abbreviations}

\begin{tabular}{ll} 
MKs & Megakaryocytes \\
miRNA & MicroRNA \\
mRNA & Messenger RNA \\
TLRs & Toll-like receptors \\
IL-1 $\beta$ & Interleukin-1 $\beta$ \\
LPS & Lipopolysaccharide \\
GO & Gene ontology \\
ICU & Intensive care unit \\
RT & Room temperature \\
PRP & Platelet-rich plasma \\
LDP & Leukocyte-depleted platelet \\
UPL & Universal ProbeLibrary \\
cDNA & Complementary DNA \\
FBS & Fetal bovine serum \\
LBP & Lipoprotein binding protein \\
TNF- $\alpha$ & Tumor necrosis factor- $\alpha$ \\
NF- B & Nuclear factor-kappa B \\
WBC & White blood cell \\
MPV & Mean platelet volume \\
CRP & C-reactive protein \\
PCT & Procalcitonin \\
DE & Differentially expressed \\
PLT & platelet \\
MAPK & mitogen-activated protein kinase \\
ERK1/2 & extracellular signal-regulated kinase 1/2 \\
JNK & c-Jun N-terminal kinase \\
& \\
\hline
\end{tabular}




\section{References}

1. Singer, M.; Deutschman, C.S.; Seymour, C.W.; Shankar-Hari, M.; Annane, D.; Bauer, M.; Bellomo, R.; Bernard, G.R.; Chiche, J.D.; Coopersmith, C.M.; et al. The Third International Consensus Definitions for Sepsis and Septic Shock (Sepsis-3). JAMA 2016, 315, 801-810. [CrossRef] [PubMed]

2. Vardon-Bounes, F.; Ruiz, S.; Gratacap, M.P.; Garcia, C.; Payrastre, B.; Minville, V. Platelets Are Critical Key Players in Sepsis. Int. J. Mol. Sci. 2019, 20, 3494. [CrossRef] [PubMed]

3. Russwurm, S.; Vickers, J.; Meier-Hellmann, A.; Spangenberg, P.; Bredle, D.; Reinhart, K.; Lösche, W. Platelet and leukocyte activation correlate with the severity of septic organ dysfunction. Shock 2002, 17, 263-268. [CrossRef] [PubMed]

4. Gawaz, M.; Dickfeld, T.; Bogner, C.; Fateh-Moghadam, S.; Neumann, F.J. Platelet function in septic multiple organ dysfunction syndrome. Intensive Care Med. 1997, 23, 379-385. [CrossRef]

5. Akinosoglou, K.; Theodoraki, S.; Xanthopoulou, I.; Perperis, A.; Gkavogianni, T.; Pistiki, A.; Giamarellos-Bourboulis, E.; Gogos, C.A. Platelet reactivity in sepsis syndrome: Results from the PRESS study. Eur. J. Clin. Microbiol. Infect. Dis. 2017, 36, 2503-2512. [CrossRef]

6. Yaguchi, A.; Lobo, F.L.; Vincent, J.L.; Pradier, O. Platelet function in sepsis. J. Thromb. Haemost. 2004, 2, 2096-2102. [CrossRef]

7. Adamzik, M.; Görlinger, K.; Peters, J.; Hartmann, M. Whole blood impedance aggregometry as a biomarker for the diagnosis and prognosis of severe sepsis. Crit Care 2012, 16, R204. [CrossRef]

8. Assinger, A.; Schrottmaier, W.C.; Salzmann, M.; Rayes, J. Platelets in Sepsis: An Update on Experimental Models and Clinical Data. Front. Immunol. 2019, 10, 1687. [CrossRef]

9. Kappelmayer, J.; Nagy, B., Jr.; Miszti-Blasius, K.; Hevessy, Z.; Setiadi, H. The emerging value of P-selectin as a disease marker. Clin. Chem. Lab. Med. 2004, 42, 475-486. [CrossRef]

10. Rondina, M.T.; Carlisle, M.; Fraughton, T.; Brown, S.M.; Miller, R.R., 3rd; Harris, E.S.; Weyrich, A.S.; Zimmerman, G.A.; Supiano, M.A.; Grissom, C.K. Platelet-monocyte aggregate formation and mortality risk in older patients with severe sepsis and septic shock. J. Gerontol. A Biol. Sci. Med. Sci. 2015, 70, 225-231. [CrossRef]

11. Mosad, E.; Elsayh, K.I.; Eltayeb, A.A. Tissue factor pathway inhibitor and P-selectin as markers of sepsis-induced non-overt disseminated intravascular coagulopathy. Clin. Appl. Thromb. Hemost. 2011, 17, 80-87. [CrossRef] [PubMed]

12. Andonegui, G.; Kerfoot, S.M.; McNagny, K.; Ebbert, K.V.; Patel, K.D.; Kubes, P. Platelets express functional Toll-like receptor-4. Blood 2005, 106, 2417-2423. [CrossRef] [PubMed]

13. Schattner, M. Platelet TLR4 at the crossroads of thrombosis and the innate immune response. J. Leukoc. Biol. 2019, 105, 873-880. [CrossRef]

14. Beaulieu, L.M.; Lin, E.; Morin, K.M.; Tanriverdi, K.; Freedman, J.E. Regulatory effects of TLR2 on megakaryocytic cell function. Blood 2011, 117, 5963-5974. [CrossRef] [PubMed]

15. Landry, P.; Plante, I.; Ouellet, D.L.; Perron, M.P.; Rousseau, G.; Provost, P. Existence of a microRNA pathway in anucleate platelets. Nat. Struct. Mol. Biol. 2009, 16, 961-966. [CrossRef] [PubMed]

16. Rondina, M.T.; Weyrich, A.S. Regulation of the genetic code in megakaryocytes and platelets. J. Thromb. Haemost. 2015, 13 Suppl. 1, S26-S32. [CrossRef]

17. Nagalla, S.; Shaw, C.; Kong, X.; Kondkar, A.A.; Edelstein, L.C.; Ma, L.; Chen, J.; McKnight, G.S.; López, J.A.; Yang, L.; et al. Platelet microRNA-mRNA coexpression profiles correlate with platelet reactivity. Blood 2011, 117, 5189-5197. [CrossRef]

18. Rowley, J.W.; Chappaz, S.; Corduan, A.; Chong, M.M.; Campbell, R.; Khoury, A.; Manne, B.K.; Wurtzel, J.G.; Michael, J.V.; Goldfinger, L.E.; et al. Dicer1-mediated miRNA processing shapes the mRNA profile and function of murine platelets. Blood 2016, 127, 1743-1751. [CrossRef]

19. Miao, X.; Rahman, M.F.; Jiang, L.; Min, Y.; Tan, S.; Xie, H.; Lee, L.; Wang, M.; Malmström, R.E.; Lui, W.O.; et al. Thrombin-reduced miR-27b attenuates platelet angiogenic activities in vitro via enhancing platelet synthesis of anti-angiogenic thrombospondin-1. J. Thromb. Haemost. 2018, 16, 791-801. [CrossRef]

20. Shashkin, P.N.; Brown, G.T.; Ghosh, A.; Marathe, G.K.; McIntyre, T.M. Lipopolysaccharide is a direct agonist for platelet RNA splicing. J. Immunol. 2008, 181, 3495-3502. [CrossRef] 
21. Rondina, M.T.; Schwertz, H.; Harris, E.S.; Kraemer, B.F.; Campbell, R.A.; Mackman, N.; Grissom, C.K.; Weyrich, A.S.; Zimmerman, G.A. The septic milieu triggers expression of spliced tissue factor mRNA in human platelets. J. Thromb. Haemost. 2011, 9, 748-758. [CrossRef] [PubMed]

22. Middleton, E.A.; Rowley, J.W.; Campbell, R.A.; Grissom, C.K.; Brown, S.M.; Beesley, S.J.; Schwertz, H.O.R.; Kosaka, Y.; Manne, B.K.; Krauel, K.; et al. Sepsis Alters the Transcriptional and Translational Landscape of Human and Murine Platelets. Blood 2019, 134, 911-923. [CrossRef] [PubMed]

23. Willeit, P.; Zampetaki, A.; Dudek, K.; Kaudewitz, D.; King, A.; Kirkby, N.S.; Crosby-Nwaobi, R.; Prokopi, M.; Drozdov, I.; Langley, S.R.; et al. Circulating microRNAs as novel biomarkers for platelet activation. Circ. Res. 2013, 112, 595-600. [CrossRef] [PubMed]

24. Martin, J.F.; Kristensen, S.D.; Mathur, A.; Grove, E.L.; Choudry, F.A. The causal role of megakaryocyte-platelet hyperactivity in acute coronary syndromes. Nat. Rev. Cardiol. 2012, 9, 658-670. [CrossRef] [PubMed]

25. Edelstein, L.C.; McKenzie, S.E.; Shaw, C.; Holinstat, M.A.; Kunapuli, S.P.; Bray, P.F. MicroRNAs in platelet production and activation. J. Thromb. Haemost. 2013, 11 Suppl. 1, 340-350. [CrossRef]

26. Fejes, Z.; Póliska, S.; Czimmerer, Z.; Káplár, M.; Penyige, A.; Gál Szabó, G.; Beke Debreceni, I.; Kunapuli, S.P.; Kappelmayer, J.; Nagy, B., Jr. Hyperglycaemia suppresses microRNA expression in platelets to increase P2RY12 and SELP levels in type 2 diabetes mellitus. Thromb. Haemost. 2017, 117, 529-542. [CrossRef]

27. Beaulieu, L.M.; Freedman, J.E. The role of inflammation in regulating platelet production and function: Toll-like receptors in platelets and megakaryocytes. Thromb. Res. 2010, 125, 205-219. [CrossRef]

28. Randriamboavonjy, V.; Fleming, I. All cut up! The consequences of calpain activation on platelet function. Vascul. Pharmacol. 2012, 56, 210-215. [CrossRef]

29. Montrucchio, G.; Bosco, O.; Del Sorbo, L.; Fascio Pecetto, P.; Lupia, E.; Goffi, A.; Omedè, P.; Emanuelli, G.; Camussi, G. Mechanisms of the priming effect of low doses of lipopoly-saccharides on leukocyte dependent platelet aggregation in whole blood. Thromb. Haemost. 2003, 90, 872-881. [CrossRef]

30. Kappelmayer, J.; Beke Debreceni, I.; Vida, A.; Antal-Szalmás, P.; Clemetson, K.J.; Nagy, B., Jr. Distinct effects of Re- and S-forms of LPS on modulating platelet activation. J. Thromb. Haemost. 2013, 11, 775-778. [CrossRef]

31. Jayachandran, M.; Brunn, G.J.; Karnicki, K.; Miller, R.S.; Owen, W.G.; Miller, V.M. In vivo effects of lipopolysaccharide and TLR4 on platelet production and activity: Implications for thrombotic risk. J. Appl. Physiol. (1985) 2007, 102, 429-433. [CrossRef] [PubMed]

32. Jayachandran, M.; Miller, V.M.; Brunn, G.J.; Owen, W.G. Platelet response as a sentinel marker of toll-like receptor 4 activation in mice. Thromb. Res. 2010, 126, 414-417. [CrossRef] [PubMed]

33. Garcia, A.; Dunoyer-Geindre, S.; Zapilko, V.; Nolli, S.; Reny, J.L.; Fontana, P. Functional Validation of microRNA-126-3p as a Platelet Reactivity Regulator Using Human Haematopoietic Stem Cells. Thromb. Haemost. 2019, 119, 254-263. [CrossRef] [PubMed]

34. Basak, I.; Bhatlekar, S.; Manne, B.K.; Stoller, M.; Hugo, S.; Kong, X.; Ma, L.; Rondina, M.T.; Weyrich, A.S.; Edelstein, L.C.; et al. miR-15a-5p regulates expression of multiple proteins in the megakaryocyte GPVI signaling pathway. J. Thromb. Haemost. 2019, 17, 511-524. [CrossRef]

35. Reithmair, M.; Buschmann, D.; Märte, M.; Kirchner, B.; Hagl, D.; Kaufmann, I.; Pfob, M.; Chouker, A.; Steinlein, O.K.; Pfaffl, M.W.; et al. Cellular and extracellular miRNAs are blood-compartment-specific diagnostic targets in sepsis. J. Cell Mol. Med. 2017, 21, 2403-2411. [CrossRef]

36. Plé, H.; Landry, P.; Benham, A.; Coarfa, C.; Gunaratne, P.H.; Provost, P. The repertoire and features of human platelet microRNAs. PLoS ONE 2012, 7, e50746. [CrossRef]

37. Sunderland, N.; Skroblin, P.; Barwari, T.; Huntley, R.P.; Lu, R.; Joshi, A.; Lovering, R.C.; Mayr, M. MicroRNA Biomarkers and Platelet Reactivity: The Clot Thickens. Circ. Res. 2017, 120, 418-435. [CrossRef]

38. Szilágyi, B.; Fejes, Z.; Pócsi, M.; Kappelmayer, J.; Nagy, B., Jr. Role of sepsis modulated circulating microRNAs. EJIFCC 2019, 30, 128-145.

39. Harrison, P.; Goodall, A.H. "Message in the platelet"-More than just vestigial mRNA! Platelets 2008, 19, 395-404. [CrossRef]

40. Lee, J.H.; Park, M.; Han, S.; Hwang, J.J.; Park, S.H.; Park, S.Y. An increase in mean platelet volume during admission can predict the prognoses of patients with pneumonia in the intensive care unit: A retrospective study. PLoS ONE 2018, 13, e0208715. [CrossRef]

41. Vardon-Bounes, F.; Mémier, V.; Marcaud, M.; Jacquemin, A.; Hamzeh-Cognasse, H.; Garcia, C.; Series, J.; Sié, P.; Minville, V.; Gratacap, M.P.; et al. Platelet activation and prothrombotic properties in a mouse model of peritoneal sepsis. Sci. Rep. 2018, 8, 13536. [CrossRef] 
42. Kirschenbaum, L.A.; Adler, D.; Astiz, M.E.; Barua, R.S.; Saha, D.; Rackow, E.C. Mechanisms of platelet-neutrophil interactions and effects on cell filtration in septic shock. Shock 2002, 17, 508-512. [CrossRef] [PubMed]

43. Freishtat, R.J.; Natale, J.; Benton, A.S.; Cohen, J.; Sharron, M.; Wiles, A.A.; Ngor, W.M.; Mojgani, B.; Bradbury, M.; Degnan, A.; et al. Sepsis alters the megakaryocyte-platelet transcriptional axis resulting in granzyme B-mediated lymphotoxicity. Am J Respir Crit. Care Med. 2009, 179, 467-473. [CrossRef] [PubMed]

44. Mukai, N.; Nakayama, Y.; Ishi, S.; Ogawa, S.; Maeda, S.; Anada, N.; Murakami, S.; Mizobe, T.; Sawa, T.; Nakajima, Y. Changes in MicroRNA Expression Level of Circulating Platelets Contribute to Platelet Defect After Cardiopulmonary Bypass. Crit. Care Med. 2018, 46, e761-e767. [CrossRef]

45. Elgheznawy, A.; Shi, L.; Hu, J.; Wittig, I.; Laban, H.; Pircher, J.; Mann, A.; Provost, P.; Randriamboavonjy, V.; Fleming, I. Dicer cleavage by calpain determines platelet microRNA levels and function in diabetes. Circ. Res. 2015, 117, 157-165. [CrossRef] [PubMed]

46. Burkhardt, J.; Blume, M.; Petit-Teixeira, E.; Hugo Teixeira, V.; Steiner, A.; Quente, E.; Wolfram, G.; Scholz, M.; Pierlot, C.; Migliorini, P.; et al. Cellular adhesion gene SELP is associated with rheumatoid arthritis and displays differential allelic expression. PLoS ONE 2014, 9, e103872. [CrossRef]

47. Tregouet, D.A.; Barbaux, S.; Escolano, S.; Tahri, N.; Golmard, J.L.; Tiret, L.; Cambien, F. Specific haplotypes of the P-selectin gene are associated with myocardial infarction. Hum. Mol. Genet. 2002, 11, 2015-2023. [CrossRef]

48. Bone, R.C.; Balk, R.A.; Cerra, F.B.; Dellinger, R.P.; Fein, A.M.; Knaus, W.A.; Schein, R.M.; Sibbald, W.J. Definitions for sepsis and organ failure and guidelines for the use of innovative therapies in sepsis. The ACCP/SCCM Consensus Conference Committee. American College of Chest Physicians/Society of Critical Care Medicine. Chest 1992, 101, 1644-1655. [CrossRef]

49. Czimmerer, Z.; Hulvely, J.; Simandi, Z.; Varallyay, E.; Havelda, Z.; Szabo, E.; Varga, A.; Dezso, B.; Balogh, M.; Horvath, A.; et al. A versatile method to design stem-loop primer-based quantitative PCR assays for detecting small regulatory RNA molecules. PLoS ONE 2013, 8, e55168. [CrossRef]

50. Fejes, Z.; Czimmerer, Z.; Szük, T.; Póliska, S.; Horváth, A.; Balogh, E.; Jeney, V.; Váradi, J.; Fenyvesi, F.; Balla, G.; et al. Endothelial cell activation is attenuated by everolimus via transcriptional and post-transcriptional regulatory mechanisms after drug-eluting coronary stenting. PLoS ONE 2018, 13, e0197890. [CrossRef] 